Article

\title{
Entropy, Entransy and Exergy Analysis of a Dual-Loop Organic Rankine Cycle (DORC) Using Mixture Working Fluids for Engine Waste Heat Recovery
}

\author{
Shuang Wang, Wei Zhang ${ }^{\mathbb{D}}$, Yong-Qiang Feng *, Xin Wang, Qian Wang, Yu-Zhuang Liu, Yu Wang \\ and Lin Yao \\ School of Energy and Power Engineering, Jiangsu University, Zhenjiang 212013, China; \\ alexjuven@ujs.edu.cn (S.W.); 18852866772@163.com (W.Z.); strxinwang@163.com (X.W.); \\ qwang@ujs.edu.cn (Q.W.); A13844628038@163.com (Y.-Z.L.); wangyu_ujs@sina.cn (Y.W.); \\ YL806023480@163.com (L.Y.) \\ * Correspondence: yqfeng@ujs.edu.cn
}

Received: 12 February 2020; Accepted: 6 March 2020; Published: 11 March 2020

check for updates

\begin{abstract}
The exergy, entropy, and entransy analysis for a dual-loop organic Rankine cycle (DORC) using a mixture of working fluids have been investigated in this study. A high-temperature (HT) loop was used to recover waste heat from internal combustion engine in $350^{\circ} \mathrm{C}$, and a low-temperature loop (LT) was used to absorb residual heat of engine exhaust gas and HT loop working fluids. Hexane/toluene, cyclopentane/toluene, and R123/toluene were selected as working fluid mixtures for HT loop, while R245fa/pentane was chosen for LT loop. Results indicated that the variation of entropy generation rate, entransy loss, entransy efficiency, and exergy loss are insensitive to the working fluids. The entransy loss rate and system net power output present the same variation trends, whereas a reverse trend for entropy generation rate and entransy efficiency, while the exergy analysis proved to be only utilized under fixed stream conditions. The results also showed that hexane/toluene is the preferred mixture fluid for DORC.
\end{abstract}

Keywords: dual-loop ORC; mixture working fluids; entropy generation; entransy loss; exergy loss

\section{Introduction}

With the depletion of coal, oil, and other non-renewable energy and the increasingly serious environmental problems, the effective use of energy has received great attention. However, the utilization rate of energy in China is only $30 \%$, especially the recovery of low-grade waste heat energy. The recovery technology has become an important research topic. The organic Rankine cycle (ORC) has been proved an environmentally friendly and efficient solution for waste heat recovery. Dai et al. [1] choose exergy efficiency as objective function, and found that ORCs performed better cycles using water. Bombarda et al. [2] compared thermodynamic performance between Kalina cycle and ORC. They found that the environmental parameters for Kalina were too excessive to be satisfied, while ORC is more suitable. The study of ORC could provide not only necessary technical support but also create certain economic benefits for waste heat utilization.

To better improve the ORC performance, numerous researches devoted main efforts to develop new ORC configurations, such as regenerative ORC (RORC), two-staged ORC (TSORC), and DORC. Feng et al. [3] conducted thermoeconomic optimization for RORC, and found that RORC had better exergy efficiency than basic ORC by $8.1 \%$. Mago et al. [4] selected dry organic fluids to compare the regenerative ORC with basic ORC (BORC). They found that RORC could obtain higher efficiency than BORC. Gang et al. [5] designed an regenerative ORC for solar power generation. Results showed that 
regenerative ORC had negative impacts on collector efficiency but benefited improving the system efficiency. The system efficiency with regenerator could improve $3.7 \%$ higher than the one without regenerator. Roy et al. [6] researched the parametric optimization of RORC using R123 and R134a. Results proved that R123 was better for converting low grade heat, and the inlet pressure of $2.70 \mathrm{MPa}$ gave the maximum system efficiency. Franco et al. [7] analyzed the RORC recycling the geothermal resources and found that RORC could obtain significant reduction in cooling surface area in comparison to the basic ORC. Li et al. [8] analyzed the effects of organic fluids on ORC system performance. The experiments showed that the RORC efficiency could reach $7.98 \%$ and had an improvement of $1.83 \%$ than BORC. Li et al. [9] proposed a two-stage ORC (TSORC) for geothermal power generation. Results showed that TSORC could reduce the irreversible loss, while it was essential to improve power generation of low-pressure stage. Sun et al. [10] discussed the TSORC combining absorption refrigeration (TSORC-AR) and selected the residual heat of absorption refrigeration as heat source for low-pressure stage. Results indicated that TSORC-AR could generate more power, while its thermal efficiency was low. Yuan et al. [11] proposed a new deep super-cooling TSORC using R245fa and MM as working fluids. They found that the new TSORC could perform better than the basic ORC for high temperature waste heat recovery. The two-stage ORC and the regenerative ORC are combined by $\mathrm{Xi}$ et al. [12]. Results indicated that the two-stage regenerative ORC always had best thermal efficiency than TSORC or RORC.

Internal combustion engines (ICE) using fossil fuel were extensively applied to industrial machines and vehicles. It is indispensable to improve the engine efficiency to economize fuel source and reduce $\mathrm{CO}_{2}$ emission. The ORC technology adapted to the internal combustion engine waste heat recovery (ICE-WHR) has been promising to get a considerable improvement in engine total efficiency. Traditional ORC systems using low-temperature working fluids were not applicable to ICE because of the large temperature gradient and the high temperature of engine waste heat. Accordingly, many studies were focusing on the modified ORC for better performance from two main aspects.

The first solution was adding extra loops to the basic ORC to further recover the residual heat, such as dual-loop organic Rankine cycle (DORC). Shu et al. [13] proposed the DORC system that used the fluids in low-temperature side to absorb residual heat of high-temperature fluid, waste gas and coolant. They obtained the maximum output power of $36.77 \mathrm{~kW}$ and exergy efficiency of $55.05 \%$. Choi et al. [14] used DORC to recover heat of container ship engines. Water and R1234yf were selected as fluids of HT and LT loop, respectively. The final exhaust was reused to the propulsion, resulting in the reduction of fuel loss and $\mathrm{CO}_{2}$ emissions by about $6.06 \%$. The DORC was also proposed for the engine exhaust recovery of long-distance transportation vehicles [15]. Botaghchi et al. [16] investigated a cascade ORC with a refrigeration loop and obtained better operation parameters by optimization and decision-making. Sun et al. [17] found that higher high-level and low-level evaporation pressures in DORC caused higher investment cost, while DORC had better thermodynamic performance than BORC.

The second solution was to select high-temperature fluids that could break the limitation of thermal decomposition temperature or adopt the mixture working fluids to have a better temperature matching in thermal transfer processes. The available energy loss could decrease with the decrease of irreversible entropy increase because of the temperature slip during phase transition. The research showed that more serious the temperature slip, the more matching the temperatures between refrigerants and cold or heat source. Oyewunmi et al. [18] researched the thermodynamic and economic performance of basic ORC using different working fluid mixtures. They found that 0.5 pentane/ 0.5 hexane and $0.6 \mathrm{R} 245 \mathrm{fa} / 0.4 \mathrm{R} 227$ ea has better thermodynamic performance, while the pentane and R245fa could obtain better economic performance. Wang et al. [19] designed a control strategy for ORC to adjust the composition of zeotropic mixtures according to the environmental parameters. Results showed that ORC using R245fa/R134a can have a higher thermal efficiency than Kalina cycle by $20-30 \%$. Collings et al. [20] analyzed the dynamic ORC performance using R245fa/R134a as the working fluid and found that the energy generation could be improved by $20 \%$ under continental climates. Oyewunmi et 
al. [21] investigated an ORC system with CHP using working fluid mixtures. Results demonstrated that using 0.7 octane/ 0.3 pentane could obtain highest exergy efficiency. Another investigation by Oyewunmi et al. [22] showed that using more volatile fluids could obtain higher efficiency and lower cost than mixtures. Lecompte et al. [23] made specific exergy analysis on the ORC using working fluid mixtures, expressing that the mixtures had $7-14 \%$ higher exergy efficiency than pure refrigerants. Feng et al. [24] analyzed the entransy and entropy dissipation of basic ORC. They found that the optimal entropy generation was obtained by $0.6 \mathrm{R} 245 \mathrm{fa} / 0.4 \mathrm{R} 152 \mathrm{a}$, while the entransy dissipation is independent of mixture component. Zhang et al. [25] compared two groups of fluids: hydrocarbon (toluene, cyclohexane, hexane, isohexane, pentane, benzene) and common fluids (R123, R245fa, R245ca, R134). Results indicated that the using hydrocarbons had higher energy and exergy performance. Another simulation carried out by Baldi et al. [26] demonstrated that cyclohexane and benzene could best save the ship engine fuel, followed by toluene, while R245fa and R236ea performed worst. The alkanes are good environment-friendly working substances because they do not contain chlorine and their greenhouse effect is low, but most of them are much flammable and explosive. The hydrofluorocarbons also do not contain chlorine atoms, while their global warming potential value is high. The mixture of hydrofluorocarbons and alkanes complement each other.

As mentioned above, the analyses of ORCs were mainly around energy and exergy performance. Limited studies considered the entropy, exergy, and entransy analysis simultaneously. Meanwhile, the researches using mixture working fluids for DORC were not well studied. Therefore, this study conducted a detailed parametric analysis of DORC using mixture working fluids, including the entropy, exergy, and entransy analysis.

\section{Modeling}

\subsection{System Description of DORC}

The flow diagram of DORC is presented in Figure 1, including two loops with different temperature ranges, which are connected with a shared heat exchanger.

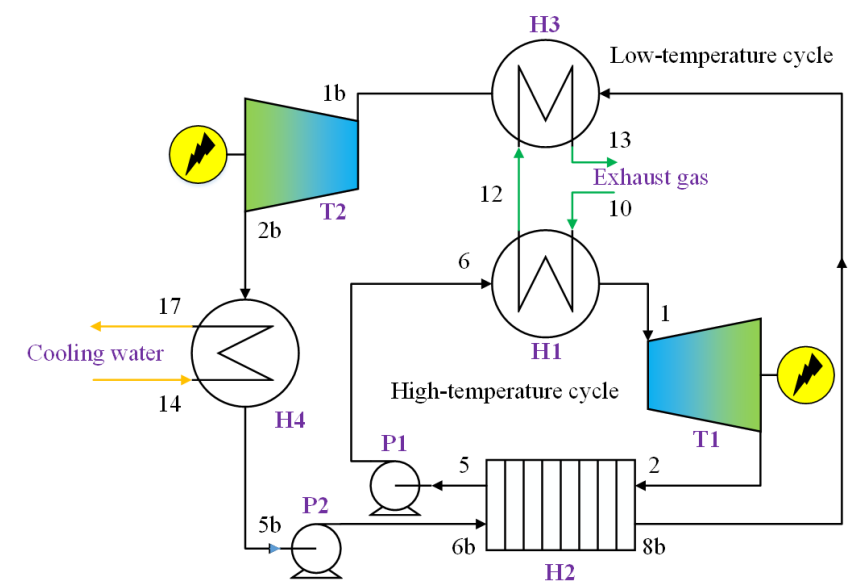

Figure 1. Flow diagram of dual-loop organic Rankine cycle (DORC) system.

The temperature-entropy diagram of DORC system is shown in Figure 2 based on hexane/toluene. In HT loop, the organic fluid from the shared heat exchanger (H2) is first converted to high-pressure state in pump (P1), then the fluid absorbs the exhaust gas heat in evaporator (H1) and is converted to high-temperature, high-pressure state. Then the overheated fluid starts expanding in expander (T1) to produce power. Afterwards, the low-temperature vapor is cooled in shared heat exchanger and flows into the pump for next cycle. 


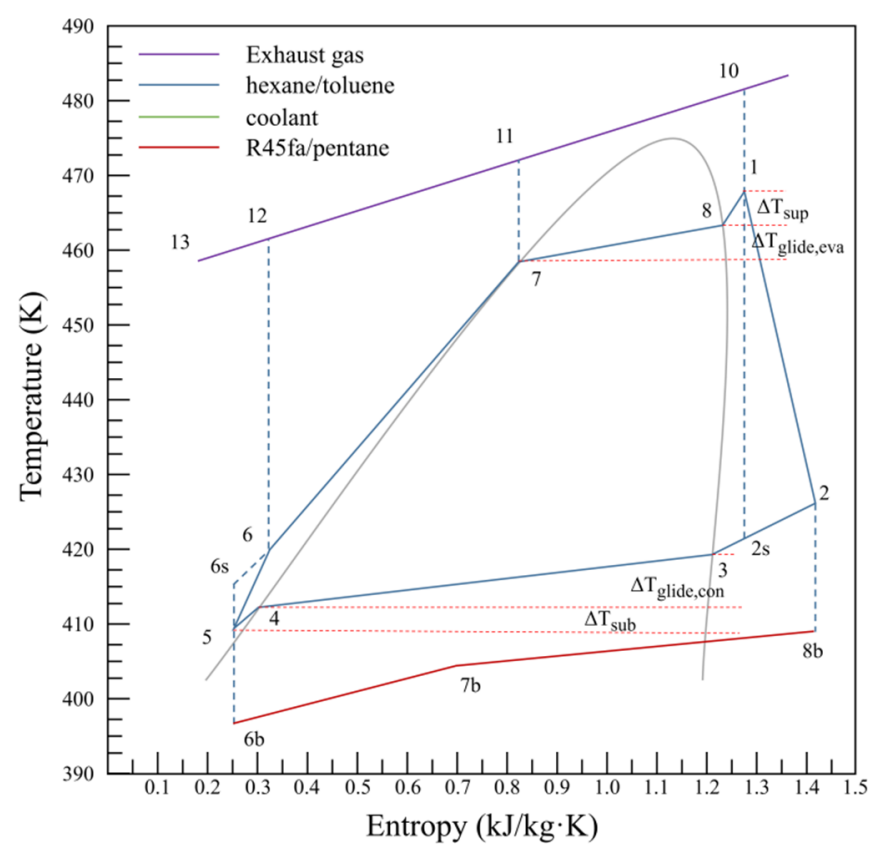

(a)

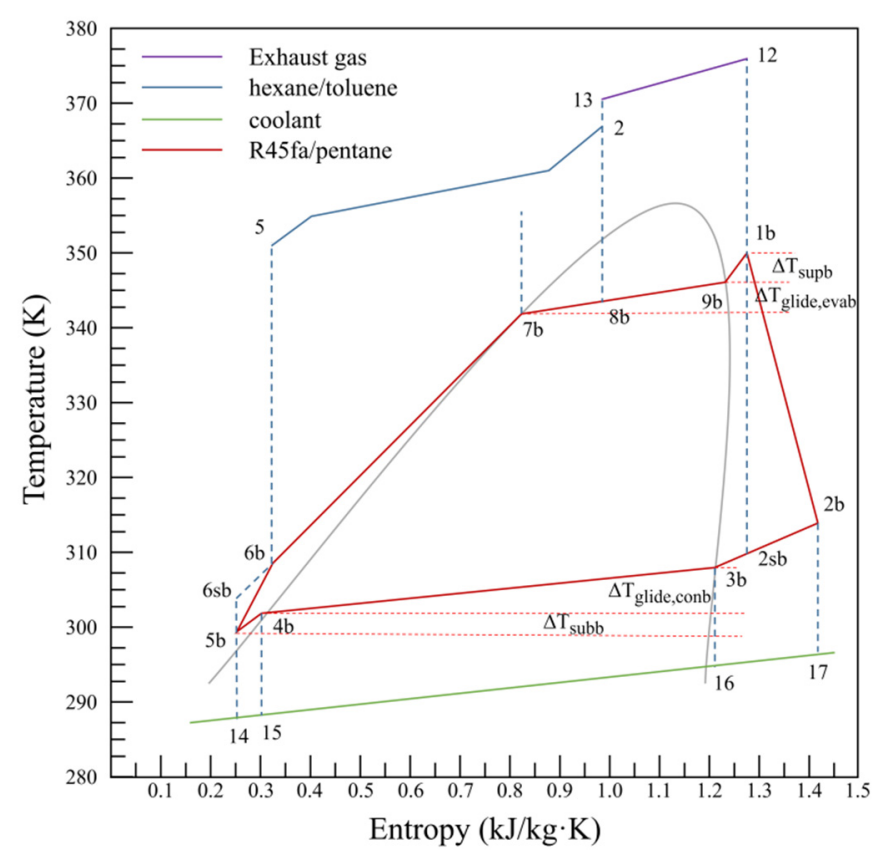

(b)

Figure 2. T-s diagram for the system: (a) The high-temperature loop; (b) the low-temperature loop.

Similar to HT loop, the low-temperature fluid from condenser (H4) is first pumped. Then the working fluid flows into heat exchangers ( $\mathrm{H} 2, \mathrm{H} 3)$ sequentially and absorbs residual heat of heat source and HT loop fluid, respectively. The saturated or superheated fluid enters the expander (T2) and expands to produce energy, and the pressure decreases to a prescribed condensation pressure. Eventually, the low-temperature loop fluid is cooled in condenser ( $\mathrm{H} 4)$ and flows into the pump for recycle. 


\subsection{Working Fluids Selection}

Working fluids selection has a significant influence on ORC performance. Hydrocarbons (HCs) such as alkanes could perform great in high temperature ORCs. Their high critical temperature characteristics could result in excellent matching between working fluids and heat source. Toluene could get more power output than others in thermodynamic investigation, as introduced by Neto et al. [27]. Song et al. [28] selected cyclohexane, benzene, and toluene as working fluids for HT loop, while R123, R236fa, and R245fa for LT loop. Results revealed using cyclohexane and toluene in HT and R245fa in LT could increase total net power output. Shu et al. [29] used cyclohexane, cyclopentane, benzene, and two retardants for combination. Lecompte et al. [30] made exergy analysis and found that using R245fa/pentane could maximize the power output under low temperature environment (120-160 $\left.{ }^{\circ} \mathrm{C}\right)$. Feng et al. [31] discussed the ORC performance using R245fa, pentane, and their mixture. They found that using $0.5 \mathrm{R} 245 \mathrm{fa} / 0.5$ pentane could obtain a low thermodynamic performance and a medium economic performance than pure fluids. Hence, hexane/toluene, cyclopentane/toluene, and R123/toluene are chosen as the working fluids for HT loop, while 0.5 pentane/0.5 R245fa is selected for LT loop. Table 1 lists the major thermodynamic properties of working fluids.

Table 1. Major properties of working fluids.

\begin{tabular}{cccccc}
\hline Fluids & $\begin{array}{c}\text { Molar Mass } \\
\text { (g/mol) }\end{array}$ & $\begin{array}{c}\text { Triple Point } \\
\text { Temperature (K) }\end{array}$ & $\begin{array}{c}\text { Standard Boiling } \\
\text { Point (K) }\end{array}$ & $\begin{array}{c}\text { Critical } \\
\text { Temperature (K) }\end{array}$ & $\begin{array}{c}\text { Critical } \\
\text { Pressure (MPa) }\end{array}$ \\
\hline hexane & 86.18 & 177.83 & 341.86 & 507.82 & 3.03 \\
toluene & 92.14 & 178 & 383.75 & 591.75 & 4.13 \\
cyclopentane & 70.13 & 179.72 & 322.4 & 511.69 & 4.51 \\
pentane & 72.15 & 143.47 & 309.21 & 469.7 & 3.37 \\
R123 & 152.93 & 166 & 300.97 & 456.83 & 3.66 \\
R245fa & 134.05 & 171.05 & 288.3 & 427.2 & 3.65 \\
\hline
\end{tabular}

\subsection{Mathematical Modeling}

Some assumptions based on the actual and literature are made to facilitate system analysis, including:

- $\quad$ The whole system operates in a steady state.

- Ignoring the pressure drop loss and thermal radiation in heat exchangers.

- The components and thermodynamic properties of mixtures do not vary with pressure or temperature.

- $\quad$ The isentropic efficiency of expanders and pumps are 0.8 .

- The ambient temperature is set to be $10^{\circ} \mathrm{C}$.

The parameters of heat source used in this paper comes from the testing data of a six-cylinder turbocharged engine [32]. The major properties of the engine, the exhaust gas which is the heat source, are presented in Table 2. The mass fractions of main components of exhaust gas is calculated about: oxygen $=0.15$, carbon dioxide $=0.05$, water $=0.06$, nitrogen $=0.74$. The state parameters of all points are calculated by REFPROP 9.0 [33], and a simulation program combining MATLAB and REFPROP is established. Table 3 presents the major parameter assumptions of DORC.

Table 2. The main properties of engine.

\begin{tabular}{|c|c|c|c|c|c|}
\hline Property & $\begin{array}{c}\text { Power } \\
(\mathrm{kW})\end{array}$ & $\begin{array}{l}\text { Rotation Rate } \\
\text { (r/min) }\end{array}$ & $\begin{array}{l}\text { Torque } \\
\text { (N·m) }\end{array}$ & $\begin{array}{c}\text { Exhaust } \\
\text { Temperature(K) }\end{array}$ & $\begin{array}{l}\text { Exhaust Gas Mass } \\
\text { Flow Rate (kg/s) }\end{array}$ \\
\hline Value & 1000 & 1500 & 6350 & 623 & 1 \\
\hline
\end{tabular}


Table 3. Main assumptions for DORC system.

\begin{tabular}{ccc}
\hline Parameter & Sign & Value \\
\hline Environment temperature & $T_{0}$ & $283.15(\mathrm{~K})$ \\
Cold stream temperature & $T_{\mathrm{c}}$ & $288.15(\mathrm{~K})$ \\
Superheating degree & $\Delta T_{\text {sup }}, \Delta T_{\text {sup, }}$ & $5(\mathrm{~K})$ \\
Supercooling degree & $\Delta T_{\text {sub }}, \Delta T_{\text {sub,b }}$ & $0(\mathrm{~K})$ \\
Expander total efficiency & $\%$ & 80 \\
Pump total efficiency & $\%$ & 80 \\
\hline
\end{tabular}

\subsubsection{Energy Modeling}

The heat transfer rate of DORC system is:

$$
\dot{Q}_{\mathrm{g}}=\dot{m}_{\mathrm{g}}\left(h_{10}-h_{13}\right)
$$

where $\dot{m}_{\mathrm{g}}$ represents the exhaust gas mass flow rate; where $h_{10}$ and $h_{13}$ represent specific enthalpies at heat source import and export, respectively.

There are two evaporators for DORC, one is for HT loop and the other is for LT loop. The heat released in high-temperature evaporator is:

$$
\dot{Q}_{\mathrm{eva}}=\dot{m}_{\mathrm{g}}\left(h_{10}-h_{12}\right)
$$

where $h_{12}$ represents heat source specific enthalpy at high-temperature evaporator export. The high-temperature condenser is one of LT evaporators. The heat absorbed by the other evaporator is:

$$
\dot{Q}_{\text {evab2 }}=\dot{m}_{\mathrm{g}}\left(h_{12}-h_{13}\right)
$$

The working fluid mass flow rate in HT loop could be calculated by:

$$
\dot{m}_{\mathrm{r}}=\frac{\dot{m}_{\mathrm{g}}\left(h_{10}-h_{12}\right)}{h_{1}-h_{6}}
$$

where $h_{6}$ and $h_{1}$ are the specific enthalpies at high-temperature evaporator import and export, respectively.

The work capacity of high-temperature expander is:

$$
\dot{W}_{\mathrm{t}}=\dot{m}_{\mathrm{r}} \cdot\left(h_{1}-h_{2}\right)=\dot{m}_{\mathrm{r}} \cdot\left(h_{1}-h_{2 \mathrm{~s}}\right) \cdot \eta_{\mathrm{t}}
$$

where $\eta_{\mathrm{t}}$ represents expander isentropic efficiency; $h_{2 \mathrm{~s}}$ and $h_{2}$ represent ideal and actual specific enthalpies at high-temperature expander export, respectively.

The working fluid mass flow in low-temperature loop can be calculated by:

$$
\dot{m}_{\mathrm{rb}}=\frac{\dot{m}_{\mathrm{r}}\left(h_{2}-h_{5}\right)}{h_{8 \mathrm{~b}}-h_{6 \mathrm{~b}}}
$$

where $h_{5}$ represents specific enthalpy at high-temperature pump import; $h_{8 \mathrm{~b}}$ and $h_{6 \mathrm{~b}}$ represent specific enthalpies of low-temperature loop fluid at shared heat exchanger import and export, respectively.

Similarly, the power generated by low-temperature expander is:

$$
\dot{W}_{\mathrm{tb}}=\dot{m}_{\mathrm{rb}} \cdot\left(h_{1 \mathrm{~b}}-h_{2 \mathrm{~b}}\right)=\dot{m}_{\mathrm{rb}} \cdot\left(h_{1 \mathrm{~b}}-h_{2 \mathrm{sb}}\right) \cdot \eta_{\mathrm{t}}
$$

where $h_{1 \mathrm{~b}}$ represents specific enthalpy at low-temperature expander import; $h_{2 \mathrm{sb}}$ and $h_{2 \mathrm{~b}}$ are ideal and actual specific enthalpies at low-temperature expander export, respectively. 
The pump power consumption is:

$$
\begin{gathered}
\dot{W}_{\mathrm{p}}=\dot{m}_{\mathrm{r}} \cdot\left(h_{6}-h_{5}\right)=\frac{\dot{m}_{\mathrm{r}} \cdot\left(h_{6 \mathrm{~s}}-h_{5}\right)}{\eta_{\mathrm{p}}} \\
\dot{W}_{\mathrm{pb}}=\dot{m}_{\mathrm{rb}} \cdot\left(h_{6 \mathrm{~b}}-h_{5 \mathrm{~b}}\right)=\frac{\dot{m}_{\mathrm{rb}} \cdot\left(h_{6 \mathrm{sb}}-h_{5 \mathrm{~b}}\right)}{\eta_{\mathrm{p}}}
\end{gathered}
$$

where $\eta_{\mathrm{p}}$ represents pump isentropic efficiency; $h_{5 \mathrm{~b}}$ represents specific enthalpy at low-temperature expander import.

$$
\begin{aligned}
& \dot{W}_{\mathrm{T}}=\dot{W}_{\mathrm{t}}+\dot{W}_{\mathrm{tb}} \\
& \dot{W}_{\mathrm{P}}=\dot{W}_{\mathrm{p}}+\dot{W}_{\mathrm{pb}}
\end{aligned}
$$

The net power output is the difference of expander work and pump consumption. Therefore, the net power output and thermal efficiency is:

$$
\begin{gathered}
\dot{W}_{\mathrm{sys}}=\dot{W}_{\mathrm{T}}-\dot{W}_{\mathrm{P}}=\dot{W}_{\mathrm{t}}+\dot{W}_{\mathrm{tb}}-\dot{W}_{\mathrm{p}}+\dot{W}_{\mathrm{pb}} \\
\eta_{\mathrm{sys}}=\frac{\dot{W}_{\text {sys }}}{\dot{Q}_{\mathrm{g}}}
\end{gathered}
$$

\subsubsection{Exergy Modeling}

Exergy analysis has proven to be an effective method for thermodynamic analysis. Exergy is the representative of energy available in thermodynamic processes. Exergy analysis considers not only the energy amount, but also the energy quality. The specific exergy of each steady point is:

$$
e_{i}=h_{i}-h_{0}-T_{0}\left(s_{i}-s_{0}\right)
$$

where $h_{i}$ and $s_{i}$ represent the state point specific enthalpy and specific entropy; where $h_{0}$ and $s_{0}$ represent the specific enthalpy and specific entropy based on the environment. Exergy loss in each process is:

$$
\dot{E}=\sum \dot{E}_{\text {in }}-\sum \dot{E}_{\text {out }}-\dot{W}
$$

where $\sum \dot{E}_{\text {in }}$ and $\sum \dot{E}_{\text {out }}$ are the total exergies input and output, respectively. Therefore, the exergy loss in each component can be described as:

$$
\begin{gathered}
\dot{E}_{\mathrm{eva}}=\dot{m}_{\mathrm{r}}\left(e_{6}-e_{1}\right)+\dot{m}_{\mathrm{g}}\left(e_{10}-e_{12}\right) \\
\dot{E}_{\mathrm{t}}=\dot{m}_{\mathrm{r}}\left(e_{1}-e_{2}\right)-\dot{W}_{\mathrm{t}} \\
\dot{E}_{\mathrm{con}}=\dot{m}_{\mathrm{r}}\left(e_{2}-e_{5}\right)+\dot{m}_{\mathrm{rb}}\left(e_{6 \mathrm{~b}}-e_{8 \mathrm{~b}}\right) \\
\dot{E}_{\mathrm{p}}=\dot{m}_{\mathrm{r}}\left(e_{5}-e_{6}\right)+\dot{W}_{\mathrm{p}} \\
\dot{E}_{\mathrm{evab} 2}=\dot{m}_{\mathrm{rb}}\left(e_{8 \mathrm{~b}}-e_{1 \mathrm{~b}}\right)+\dot{m}_{\mathrm{g}}\left(e_{12}-e_{13}\right) \\
\dot{E}_{\mathrm{tb}}=\dot{m}_{\mathrm{rb}}\left(e_{1 \mathrm{~b}}-e_{2 \mathrm{~b}}\right)-\dot{W}_{\mathrm{tb}} \\
\dot{E}_{\mathrm{conb}}=\dot{m}_{\mathrm{rb}}\left(e_{2 \mathrm{~b}}-e_{5 \mathrm{~b}}\right)+\dot{m}_{\mathrm{c}}\left(e_{14}-e_{17}\right) \\
\dot{E}_{\mathrm{pb}}=\dot{m}_{\mathrm{rb}}\left(e_{5 \mathrm{~b}}-e_{6 \mathrm{~b}}\right)+\dot{W}_{\mathrm{pb}}
\end{gathered}
$$


Therefore, the system total exergy loss is:

$$
\dot{E}_{\mathrm{sys}}=\dot{E}_{\mathrm{eva}}+\dot{E}_{\mathrm{t}}+\dot{E}_{\mathrm{con}}+\dot{E}_{\mathrm{p}}+\dot{E}_{\mathrm{evab} 2}+\dot{E}_{\mathrm{tb}}+\dot{E}_{\mathrm{conb}}+\dot{E}_{\mathrm{pb}}
$$

\subsubsection{Entropy Modeling}

The entropy generation rate in entropy analysis is related to the irreversible loss and output power, and it represents the work ability. The concept of entropy was proposed by Clausius [34] in 1854 . The larger entropy generation rate means greater irreversible loss in irreversible process. Therefore, entropy generation is always used for thermodynamic optimization. For any thermodynamic process, the entropy balance can be described as:

$$
\dot{S}_{\mathrm{g}}+\dot{S}_{\mathrm{f}}=\Delta \dot{S}
$$

where $\dot{S}_{\mathrm{g}}$ represents entropy generation rate, while $\dot{S}_{\mathrm{f}}$ represents entropy flow into the system. When the system keeps steady, the entropy change will not change with time, which means $\Delta \dot{S}$ is zero, hence, $\dot{S}_{\mathrm{g}}$ could be expressed as:

$$
\begin{gathered}
\dot{S}_{\mathrm{g}}=-\dot{S}_{\mathrm{f}}=\dot{S}_{\mathrm{f}, \text { out }}-\dot{S}_{\mathrm{f}, \text { in }} \\
\dot{S}_{\mathrm{f}, \text { in }}=\int_{T_{0}}^{T_{10}} \frac{c_{\mathrm{g}} \dot{m}_{\mathrm{g}} d T}{T}+\int_{T_{0}}^{T_{14}} \frac{c_{\mathrm{c}} \dot{m}_{\mathrm{c}} d T}{T}=c_{\mathrm{g}} \dot{m}_{\mathrm{g}} \ln \frac{T_{10}}{T_{0}}+c_{\mathrm{c}} \dot{m}_{\mathrm{c}} \ln \frac{T_{14}}{T_{0}} \\
\dot{S}_{\mathrm{f}, \text { out }}=\frac{\dot{Q}_{0}}{T_{0}}
\end{gathered}
$$

where $\dot{S}_{\mathrm{f}, \text { in }}$ and $\dot{S}_{\mathrm{f} \text {,out }}$ represent the entropies flow into and out of system, respectively; $\dot{Q}_{0}$ represents the heat flowing into the environment; $c_{\mathrm{g}}$ and $c_{c}$ represent the specific heat capacities of heat and cold source, respectively. The heat released to the environment is:

$$
\dot{Q}_{0}=c_{\mathrm{g}} \dot{m}_{\mathrm{g}}\left(T_{10}-T_{0}\right)+c_{\mathrm{c}} \dot{m}_{\mathrm{c}}\left(T_{14}-T_{0}\right)-\dot{W}_{\text {sys }}
$$

where $\dot{m}_{\mathrm{c}}$ represents cooling water mass flow rate.

\subsubsection{Entransy Modeling}

Entransy concept is first proposed by Guo et al. [35] by thermoelectric comparison. They defined entransy as the total heat transfer capacity relative to $0^{\circ} \mathrm{C}$ environment, which was similar to the electrical energy in a capacitor. Cheng et al. [36] discussed the thermodynamic process of Brayton cycles and found that calculating highest entransy could benefit parameter optimization design. Li et al. [37] conducted a model to optimize TSORC based on the entransy concept, and found that TSORC reduced the entransy dissipation because of the high average evaporation temperature. Zhu et al. [38] compared the thermodynamic performance using R123 and pentane. They found that entransy loss and entransy efficiency were suitable for optimization except entransy dissipation. For any object, the entransy could be expressed as:

$$
G=\frac{1}{2} U T
$$

where $U$ and $T$ represent internal energy and temperature, respectively. The internal energy could be expressed as:

$$
U=c m T
$$

where $c$ represents the specific heat capacity at constant volume.

According to the first thermodynamics law, the heat-work conversion process is:

$$
\delta Q=\mathrm{d} U+\delta W
$$


where $\delta Q$ represents endothermic rate; $\mathrm{d} U$ and $\delta W$ represents internal energy change rate and output power, respectively. The equation can be converted to:

$$
\oint T \delta Q=\oint \mathrm{d}\left(\frac{1}{2} c m T^{2}\right)+\oint T \delta W
$$

For the ORC system, $\frac{1}{2} c m T^{2}$ represents working fluid entransy, which is a state quantity. After a cycle, the equation becomes as:

$$
\oint T \delta Q=\oint T \delta W
$$
which is:

The right part is work entransy outflow. The left part is net entransy flow into working fluid,

$$
\dot{G}_{\text {net }}=\oint T \delta Q
$$

Part of entransy is used for heating or cooling, and some is used for expander work. The remaining is for low temperature source. Thus, from the perspective of heat source, the entransy loss in ORC system occurs in thermal cycle process, which could be expressed as:

$$
\dot{G}_{\text {loss }}=\dot{G}_{\text {net }}+\dot{G}_{\text {dis }}=\dot{G}_{\mathrm{h}}-\dot{G}_{1}
$$

where $\dot{G}_{\mathrm{h}}$ and $\dot{G}_{\mathrm{l}}$ represent entransy inflow from high temperature source, and entransy outflow into low temperature source; $\dot{G}_{\text {dis }}$ represents the entransy dissipation because of the temperature difference between heat and cold source.

The entransy inflow could be calculated by:

$$
\dot{G}_{\mathrm{h}}=\frac{1}{2} c_{\mathrm{g}} \dot{m}_{\mathrm{g}}\left(T_{10}^{2}-T_{0}^{2}\right)
$$

The entransy outflow can be calculated by:

$$
\dot{G}_{1}=\frac{1}{2} c_{\mathrm{c}} \dot{m}_{\mathrm{c}}\left(T_{0}^{2}-T_{14}^{2}\right)+\dot{Q}_{0} T_{0}
$$

where first part on right side is entransy flow into cold stream, and the other part is entransy loss due to heat flow released into the atmosphere. Therefore, the entransy loss rate can be expressed as:

$$
\dot{G}_{\text {loss }}=\frac{1}{2} c_{\mathrm{g}} \dot{m}_{\mathrm{g}}\left(T_{10}^{2}-T_{0}^{2}\right)+\frac{1}{2} c_{\mathrm{c}} \dot{m}_{\mathrm{c}}\left(T_{14}^{2}-T_{0}^{2}\right)+\dot{W}_{\text {sys }} T_{0}
$$

Accordingly, the entransy efficiency is

$$
G_{\mathrm{x}}=\frac{\dot{G}_{1}}{\dot{G}_{\mathrm{h}}}
$$

\section{Results and Discussion}

There are many significant parameters affecting the system performance, including evaporation temperature, condensation temperature, superheating degree, pinch point temperature difference (PPTD), and working fluid mixture component. The parametric analysis of DORC using mixture fluids is conducted. The effects of evaporation temperature and condensation temperature of HT loop and LT loop are addressed in Sections 3.1 and 3.2, respectively. The effects of superheating degree and PPTD are analyzed in Section 3.3. Eventually, the effects of working fluid mixture component are addressed in Section 3.4. 


\subsection{Effects of Evaporation Temperature and Condensation Temperature of HT Loop}

The effects of HT loop evaporation temperature on system performance are plotted in Figure 3. The HT loop evaporation temperature is in the range of $463-523 \mathrm{~K}$, and LT loop evaporation temperature is set as $403 \mathrm{~K}$. The HT and LT loop condensation temperatures are $413 \mathrm{~K}$ and $303 \mathrm{~K}$, respectively. The working fluid mixture component in HT loop is assumed as 0.5/0.5.

As shown in Figure 3a, the net output power increases first and then decreases as HT loop evaporation temperature for all mixtures, which means there is an inflection point on the curve of the net output power. The optimal evaporation temperature is $488 \mathrm{~K}$ corresponding to maximum output power $51.58 \mathrm{~kW}$ for hexane/toluene. The net output power depends on the difference of expander shaft work and pump power consumption, and the expander work accounts for the main part which is determined by the enthalpy difference between expander import and export. The fluid mass flow rate decreases nonlinearly as HT loop evaporation temperature increases. The specific enthalpy difference in evaporator shows a linear growth. Therefore, HT loop expander work presents a parabola trend. The curve characteristics for three working fluid mixtures are same, while the optimal evaporation temperatures for cyclopentane/toluene and R123/toluene are $483 \mathrm{~K}$ and $473 \mathrm{~K}$, which appear earlier than the case for hexane/toluene and the corresponding maximum output power is $48.64 \mathrm{~kW}$ and $45.61 \mathrm{~kW}$, respectively.

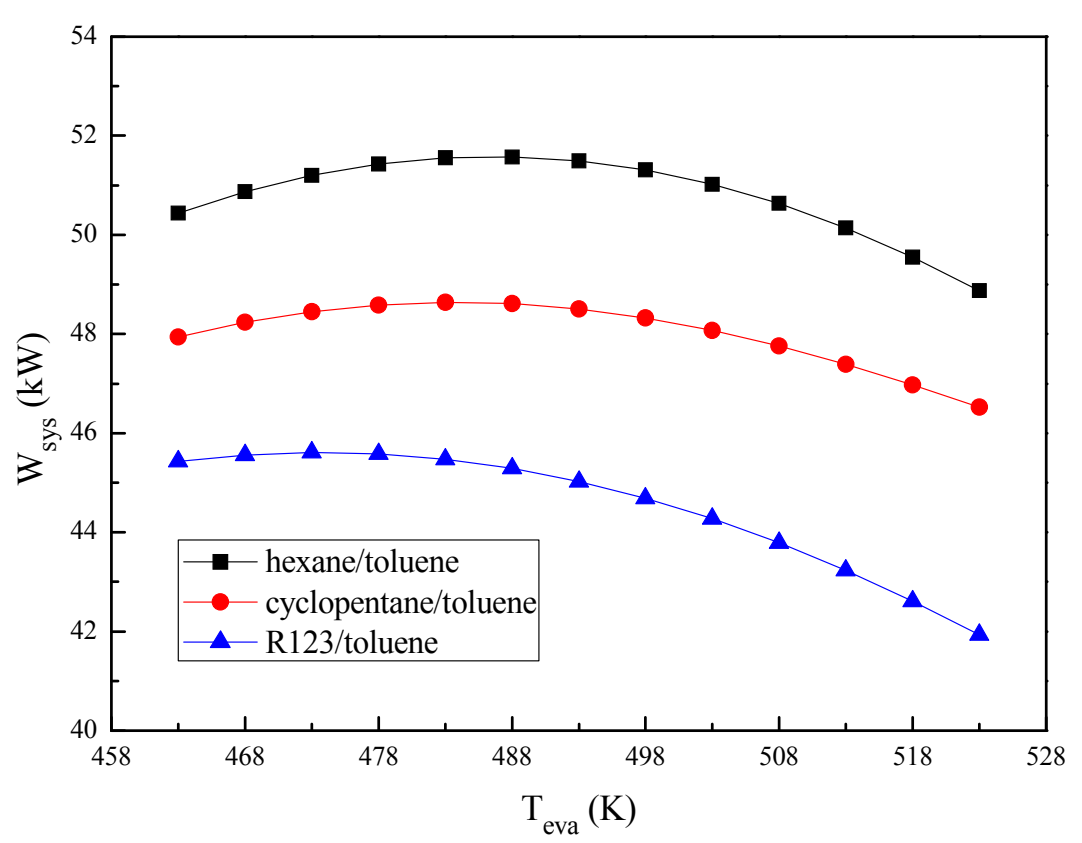

(a)

Figure 3. Cont. 


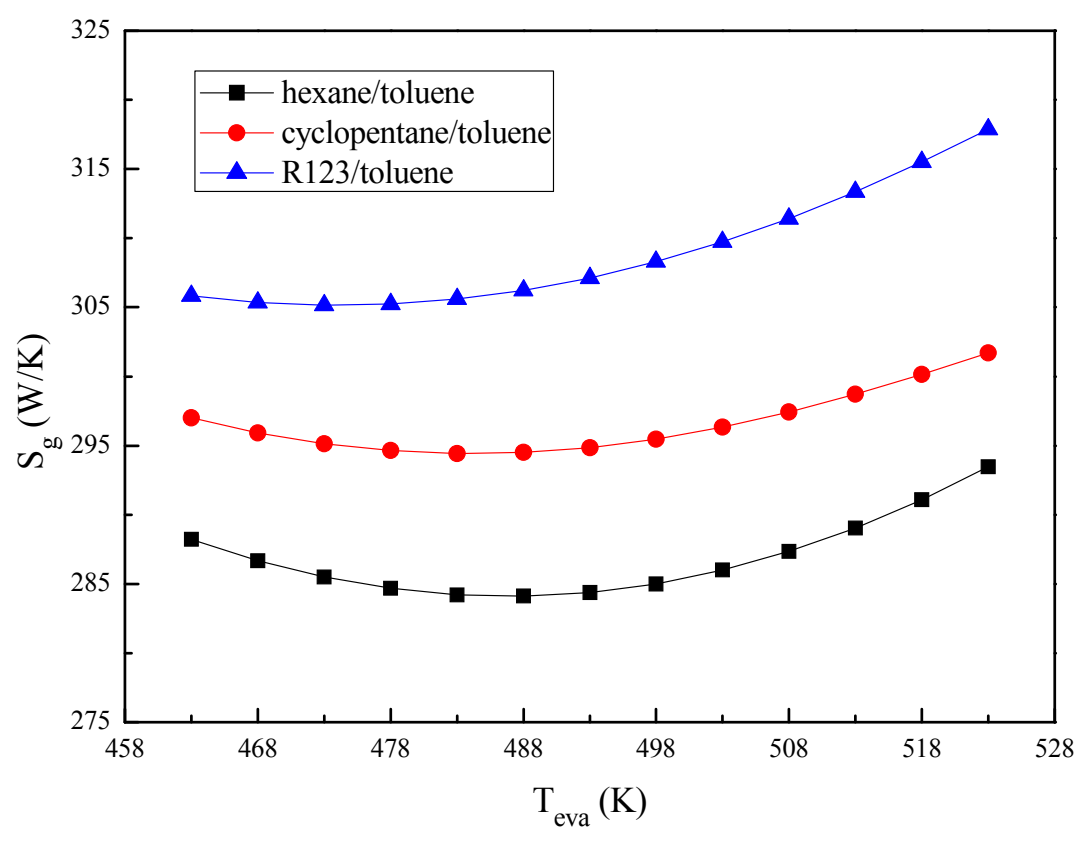

(b)

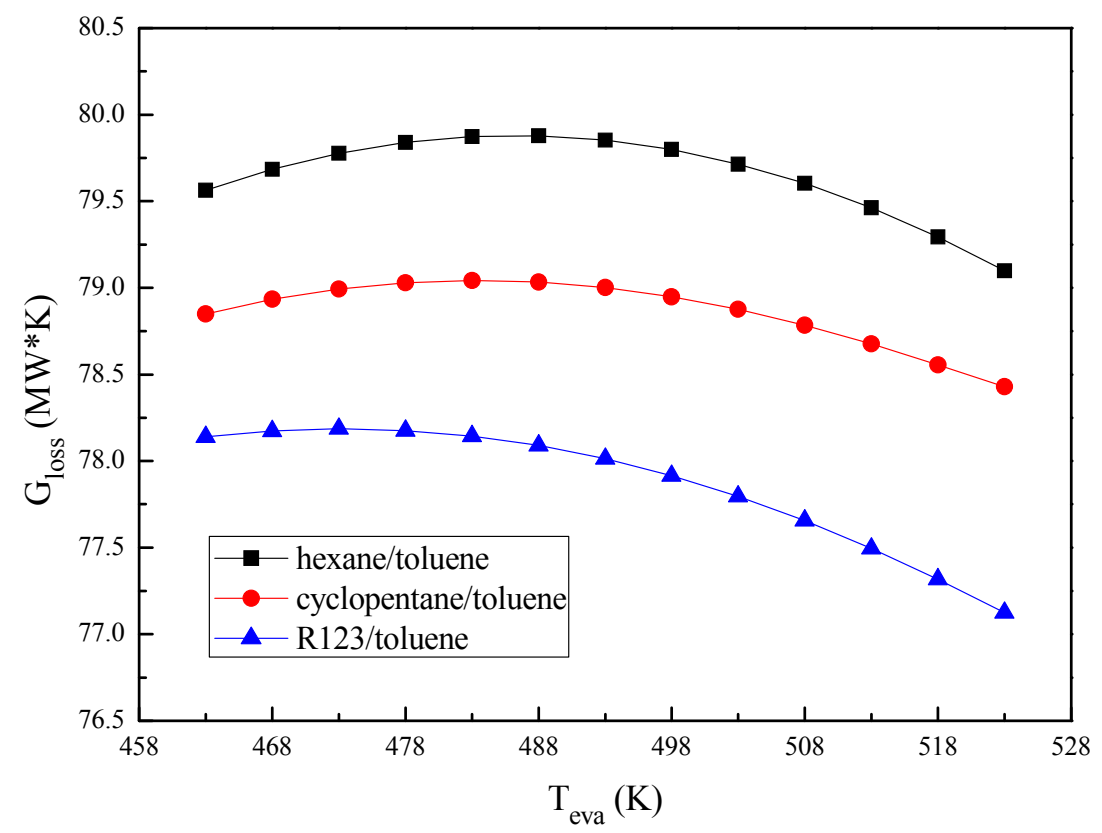

(c)

Figure 3. Cont. 


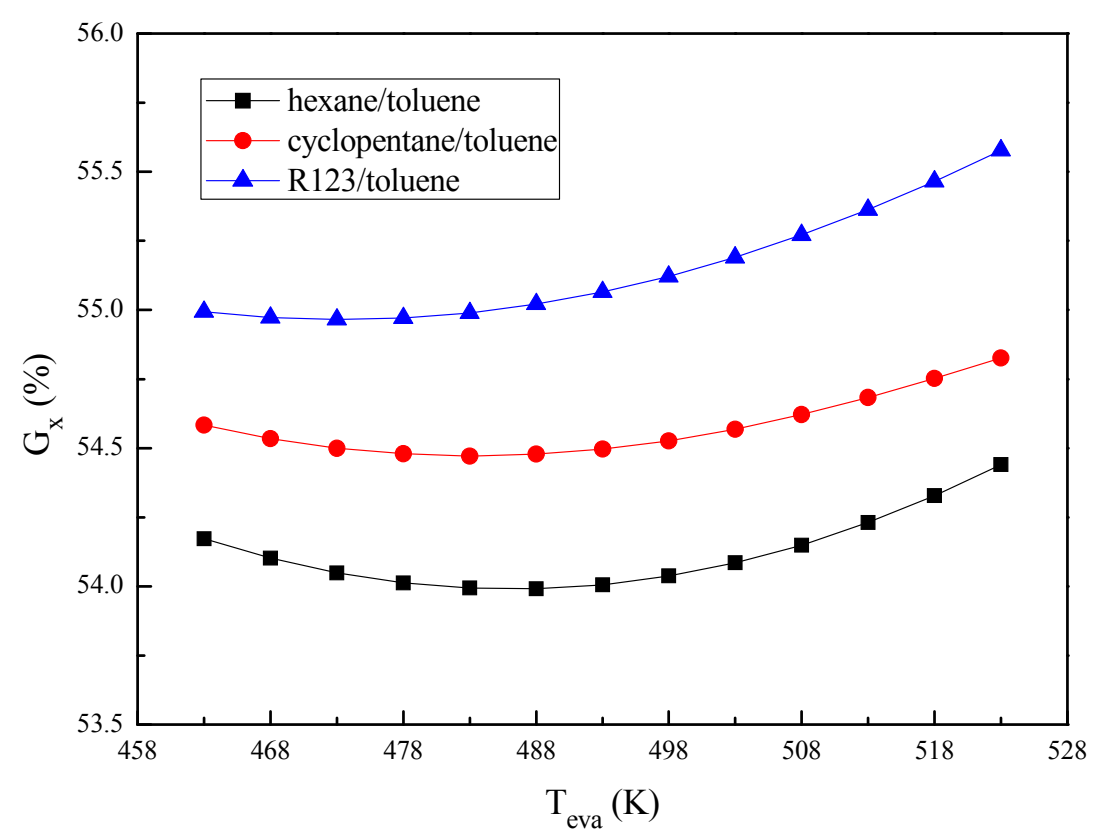

(d)

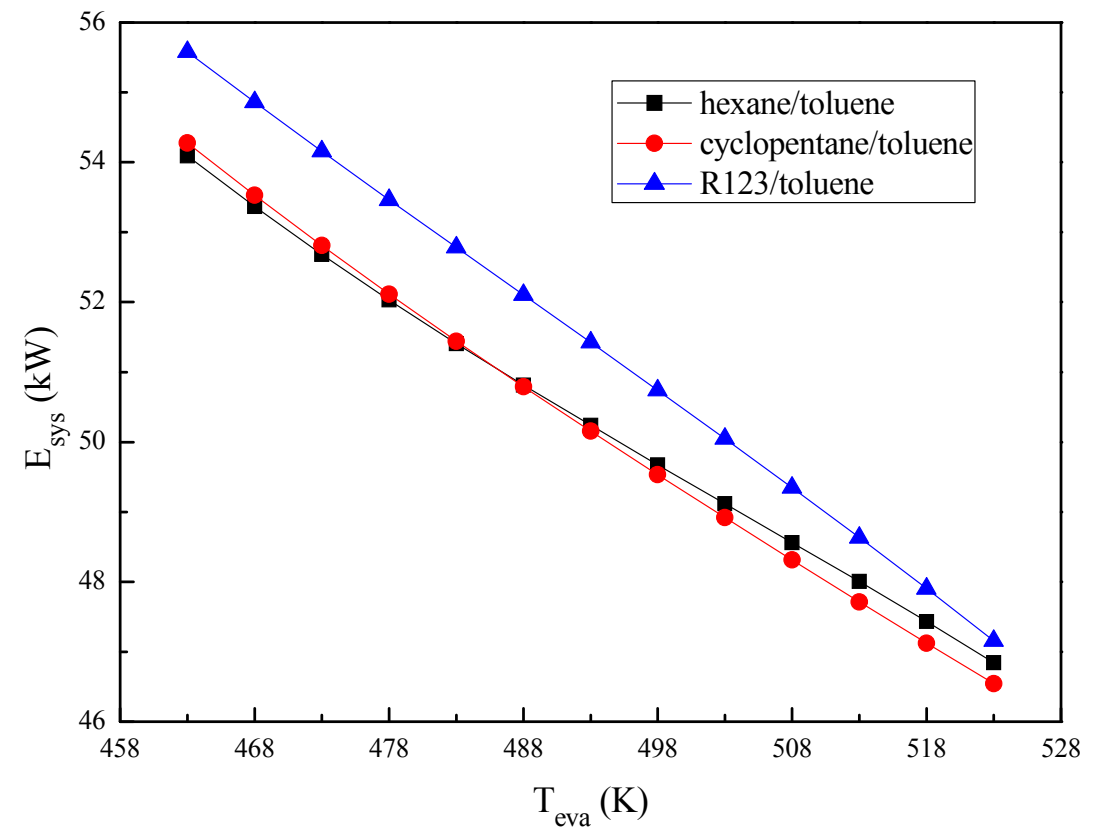

(e)

Figure 3. Effects of the high-temperature (HT) loop evaporation temperature on system performance: (a) Variation of net power output; (b) variation of entropy generation rate; (c) variation of entransy loss rate; (d) variation of entransy efficiency; (e) variation of exergy loss. 
Entropy generation is indispensable in irreversible system. As shown in Figure 3b, the entropy generation rate for hexane/toluene decreases first and then increases as HT loop evaporation temperature increases, and reaches the minimum value $0.284 \mathrm{~kW} / \mathrm{K}$ at the maximum output power point. The variation is same as the ones for cyclopentane/toluene and R123/toluene. Their minimum entropy generation rates are $0.294 \mathrm{~kW} / \mathrm{K}$ and $0.305 \mathrm{~kW} / \mathrm{K}$ respectively which are both higher than the one for hexane/toluene. Taking the system using hexane/toluene as example, when HT loop evaporation temperature falls below $488 \mathrm{~K}$, net power output keeps increasing and the water mass flow requirement decreases. As a part of the entropy flowing out of system, the section $c_{\mathrm{c}} \dot{m}_{\mathrm{c}}\left(T_{14}-T_{0}\right) / T_{0}-c_{\mathrm{c}} \dot{m}_{\mathrm{c}} \ln \left(T_{14} / T_{0}\right)$ decreases, leading to the decrease of entropy generation rate. When $T_{\text {eva }} \geq 488 \mathrm{~K}$, the net power output starts decreasing and water mass flow rate increase accordingly. The entropy generation rate yields a reverse trend because the growth rate of $\dot{W}_{\text {sys }} / T_{0}$ is larger than the decrement of $c_{\mathrm{c}} \dot{m}_{\mathrm{c}}\left(T_{14}-T_{0}\right) / T_{0}-c_{\mathrm{c}} \dot{m}_{\mathrm{c}} \ln \left(T_{14} / T_{0}\right)$. The larger entropy generation rate means the greater irreversible loss. Hence, using hexane/toluene as the working fluid is better than others from the perspective of entropy analysis.

The entransy loss rate and entransy efficiency characterize the heat transfer capability from the perspective of hot and cold steam. Figure $3 \mathrm{c}$ indicates that the entransy loss rate increases to a maximum point and then reduces gradually with the rise of HT loop temperature. The maximum entransy loss rates are $79.88 \mathrm{MW} \cdot \mathrm{K}$ (hexane/toluene), $79.04 \mathrm{MW} \cdot \mathrm{K}$ (cyclopentane/toluene), and $78.19 \mathrm{MW} \cdot \mathrm{K}$ (R123/toluene), respectively. According to the Figure 3c,d, entransy loss rate and entransy efficiency have adverse growth characteristics and the minimum entransy efficiency are 53.99\% (hexane/toluene), $54.47 \%$ (cyclopentane/toluene), and 54.97\% (R123/toluene), respectively. This proves that the system heat transfer capacity using hexane/toluene is optimal, followed by the one for cyclopentane/toluene and R123/toluene successively. It should be noted that the maximum entransy loss rates and highest power output occur under same temperature, which means there is a positive correlation between net power output and entransy loss. For theoretical study, when $T_{\text {eva }}<T_{\text {eva,op, }}$ the entransy flowing into the system keeps constant under fixed exhaust gas inlet temperature. The water mass flow rate gradually reduces, leading to the decrease of the entransy flowing into water, while the decrement is lower than the increment of the entransy loss released into the environment. Therefore, the total entransy loss keeps rising. When $T_{\text {eva }} \geq T_{\text {eva,op, }}$ the decline of the entransy flowing to the both water and environment results in the reduction of the total entransy loss.

Exergy analysis could study the energy loss during heat transfer process by comparing exergy destroyed in various components, as shown in Figure 3e. The system exergy loss decreases with the rise of HT loop temperature for all mixtures. Figure $4 \mathrm{a}-\mathrm{c}$ reveal the variations of exergy loss rate and its distributions in the DORC system. As for hexane/toluene, the pump exergy loss is small enough to be neglected compared to other components, while the exergy destroyed in the evaporator and condenser accounts for the largest proportion, which are $22-31 \%$ and $33-35 \%$ respectively. The exergy loss in heat exchangers (H1, H2, H4) and LT loop expander decreases, while that of the heat exchanger H3 and the HT loop expander increases. When the HT loop evaporation temperature increases, the exergy loss in HT loop evaporator decreases. Although HT loop mixture mass flow rate is decreasing, the exergy change between HT loop expander import and export keeps increasing, and its increment is greater than the expander work, leading to the increase of expander exergy loss. The exergy analysis of other components can be verified in the same way. It can also be found that the exergy loss distributions for three mixtures have a similar trend. 


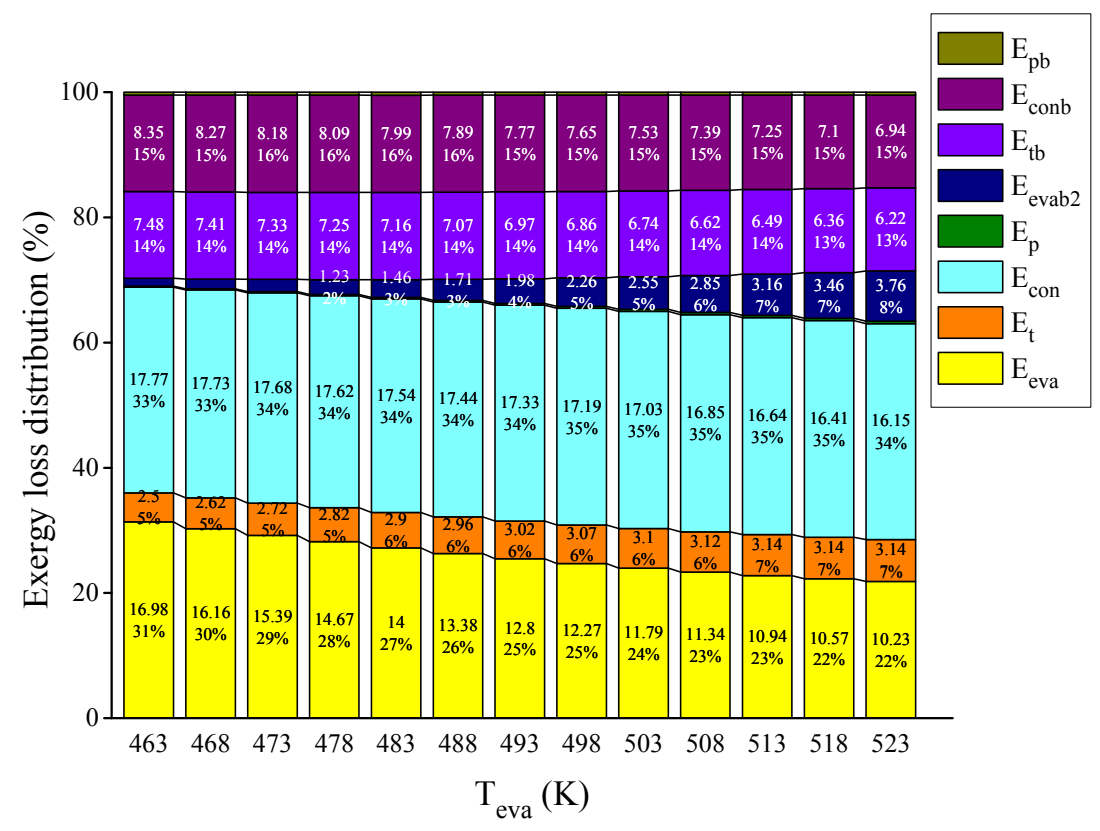

(a)

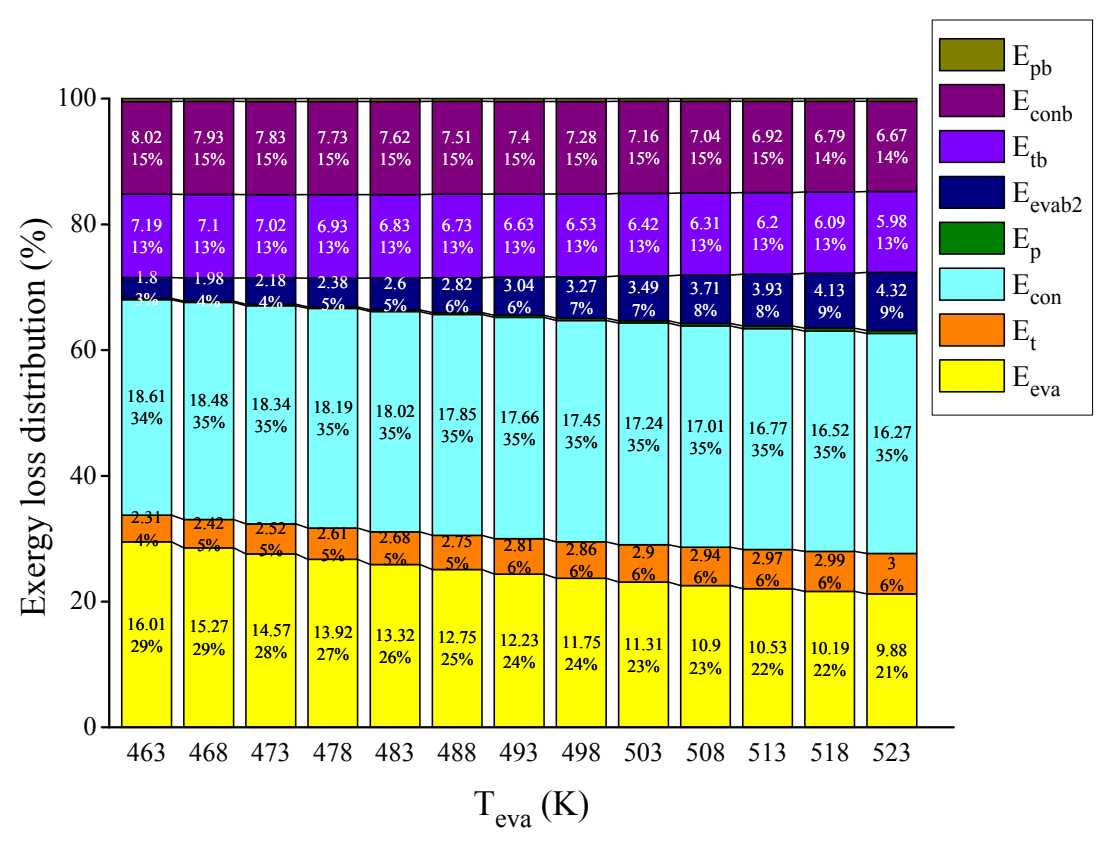

(b)

Figure 4. Cont . 


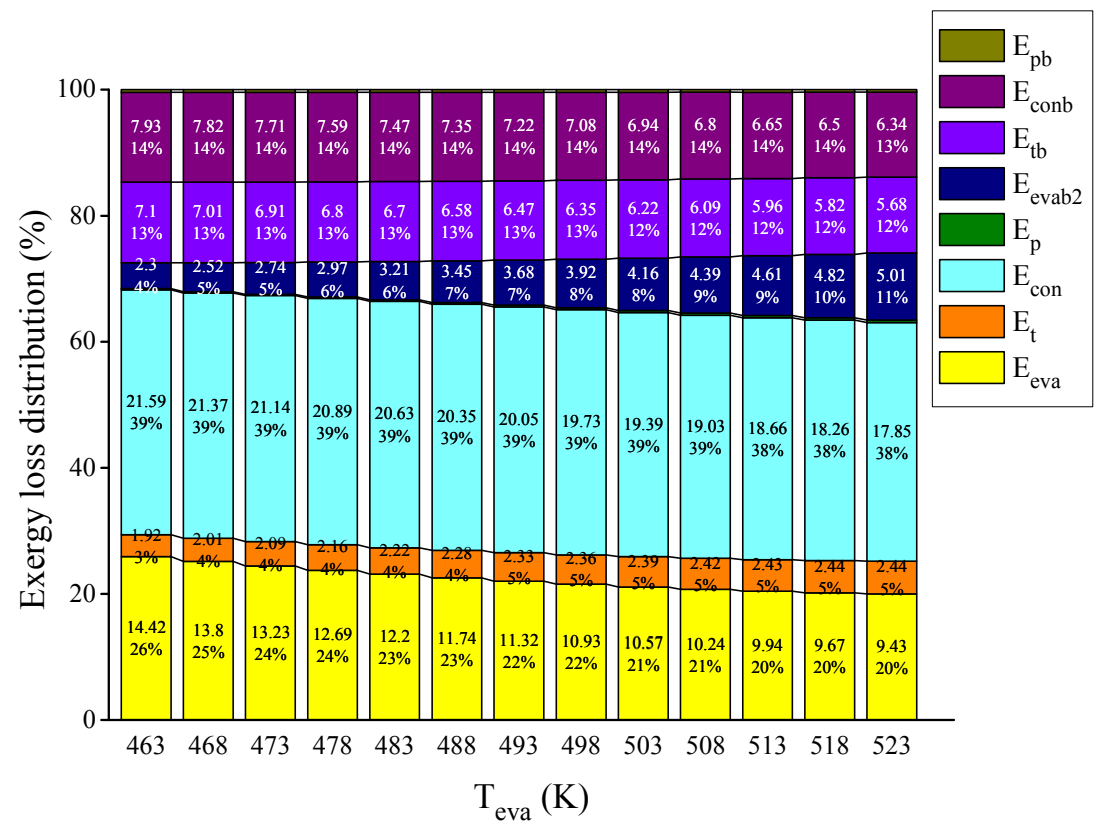

(c)

Figure 4. Variation of exergy loss distribution with HT loop evaporation temperature: (a) Hexane/toluene; (b) cyclopentane/toluene; (c) R123/toluene.

The simulation results for three mixture working fluids showed extremely similar characteristics. Thus, the researches below are only carried out for hexane/toluene as a typical case. Figure 5 presents the influence of HT loop condensation temperature on system performance. The HT loop evaporation temperature and LT loop condensation temperature are $513 \mathrm{~K}$ and $303 \mathrm{~K}$, respectively. The net power output decreases as HT loop condensation temperature rises. This phenomenon can be explained as, the HT loop fluid mass flow rate keeps constant with the rise of HT loop condensation temperature, while the specific enthalpy difference between the expander import and export continuously decreases. Therefore, the expander shaft work decreases and the net power output decreases accordingly. When HT loop condensation temperature increases gradually, the water mass flow rate gradually decreases, resulting in the decline of the section $c_{\mathrm{c}} \dot{m}_{\mathrm{c}}\left(T_{14}-T_{0}\right) / T_{0}-c_{\mathrm{c}} \dot{m}_{\mathrm{c}} \ln \left(T_{14} / T_{0}\right)$, but the dropping rate is less than that of $\dot{W}_{\text {sys }} / T_{0}$, so the entropy generation rate gradually improves. The entransy flowing into the system remains unchanged and water mass flow rate decreases, leading to the improvement of the entransy taken in from the water, while the portion is lower than the entransy loss released into the environment. Therefore, the entransy flow out of system increases, resulting in the decrease of total entransy loss rate. The curve characteristic of entransy loss rate is same as net power output and total exergy loss. The entropy generation rate is inversely proportional to the entransy loss rate as previous research results. 


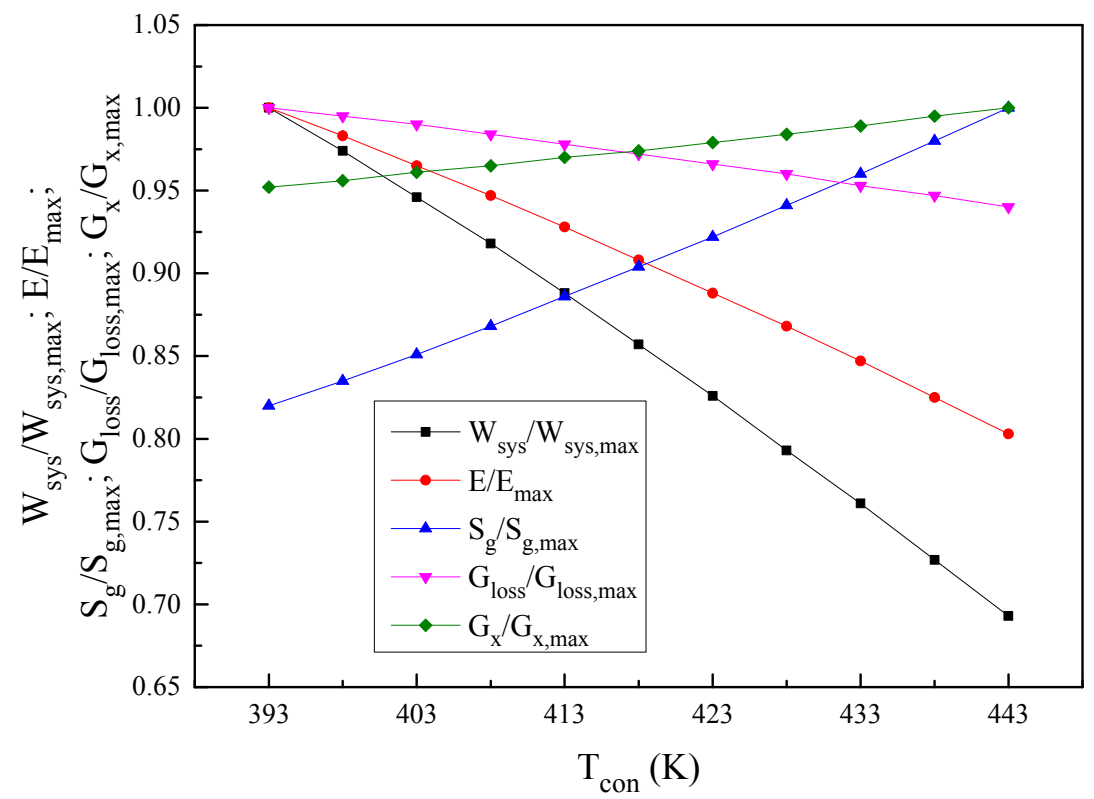

Figure 5. Effects of HT loop condensation temperature for hexane/toluene.

\subsection{Effect of Evaporation Temperature and Condensation Temperature of LT Loop}

For more discussion, some detailed 3-D coordinates are presented to describe visually the effects of the LT loop evaporation temperature and LT loop condensation temperature on system performance using hexane/toluene. The input data is set that $T_{\text {eva }}=513 \mathrm{~K}, T_{\text {con }}=423 \mathrm{~K}, T_{\text {evab }}$ varies from $363 \mathrm{~K}$ to $413 \mathrm{~K}, \mathrm{~T}_{\text {conb }}$ varies from $293 \mathrm{~K}$ to $333 \mathrm{~K}$.

Figure 6a shows that net power output increases as LT loop evaporation temperature increases. The specific enthalpy differences in LT loop expander and pump both increase as LT loop evaporation temperature increases, causing the increase of required mixture mass flow. The enthalpy difference in LT loop expander keeps rising under the comprehensive of mass flow rate and specific enthalpy. Besides, the LT loop pump power consumption is small enough to be ignored compared with the expander work; while the variation of the LT evaporation or condensation temperature could not affect the HT loop work capacity. Therefore, it can be approximated that there is similar variation between net power output and expander work, which means the net output power gradually increases as LT loop evaporation temperature and the maximum output power could reach $46 \mathrm{~kW}$. In addition, the system entropy generation rate keeps falling as shown in Figure 6b. When LT loop evaporation temperature rises, the most parameters of HT loop could not be affected. The net power output increases and the water flow requirement gradually decreases, so the section $c_{\mathrm{c}} \dot{m}_{\mathrm{c}} \ln \left(T_{14} / T_{0}\right)$ and $c_{\mathrm{c}} \dot{m}_{\mathrm{c}}\left(T_{14}-T_{0}\right) / T_{0}$ both decreases while the decrement of latter is greater, which eventually leads to the decrease of entropy generation rate. The variation indicates that the system irreversible loss increases as LT loop evaporation temperature increases. Simultaneously, the entransy flowing into the water decreases, and its decrement is lower than that of entransy loss released into the atmosphere. Therefore, the entransy loss rate keeps rising, and the system heat transfer capability will get better with the improvement of LT loop evaporation temperature, as shown in Figure 6c. 


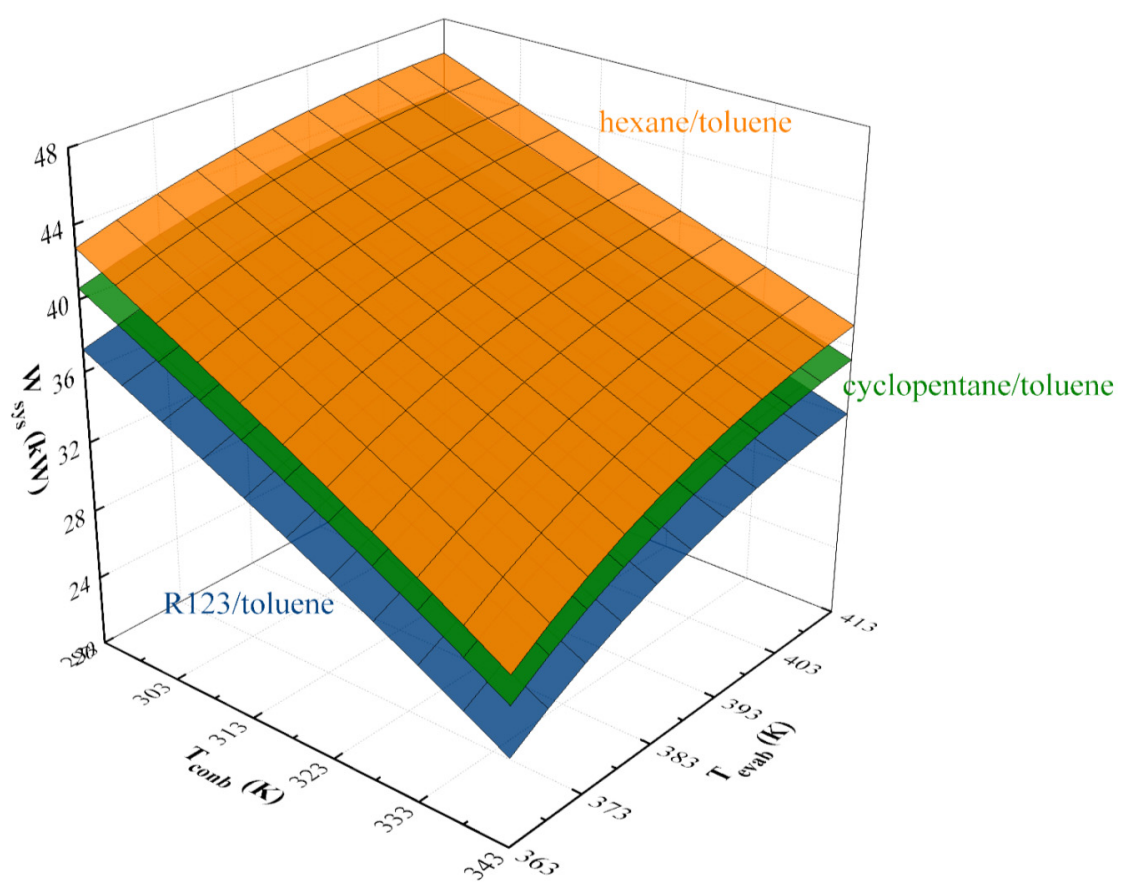

(a)

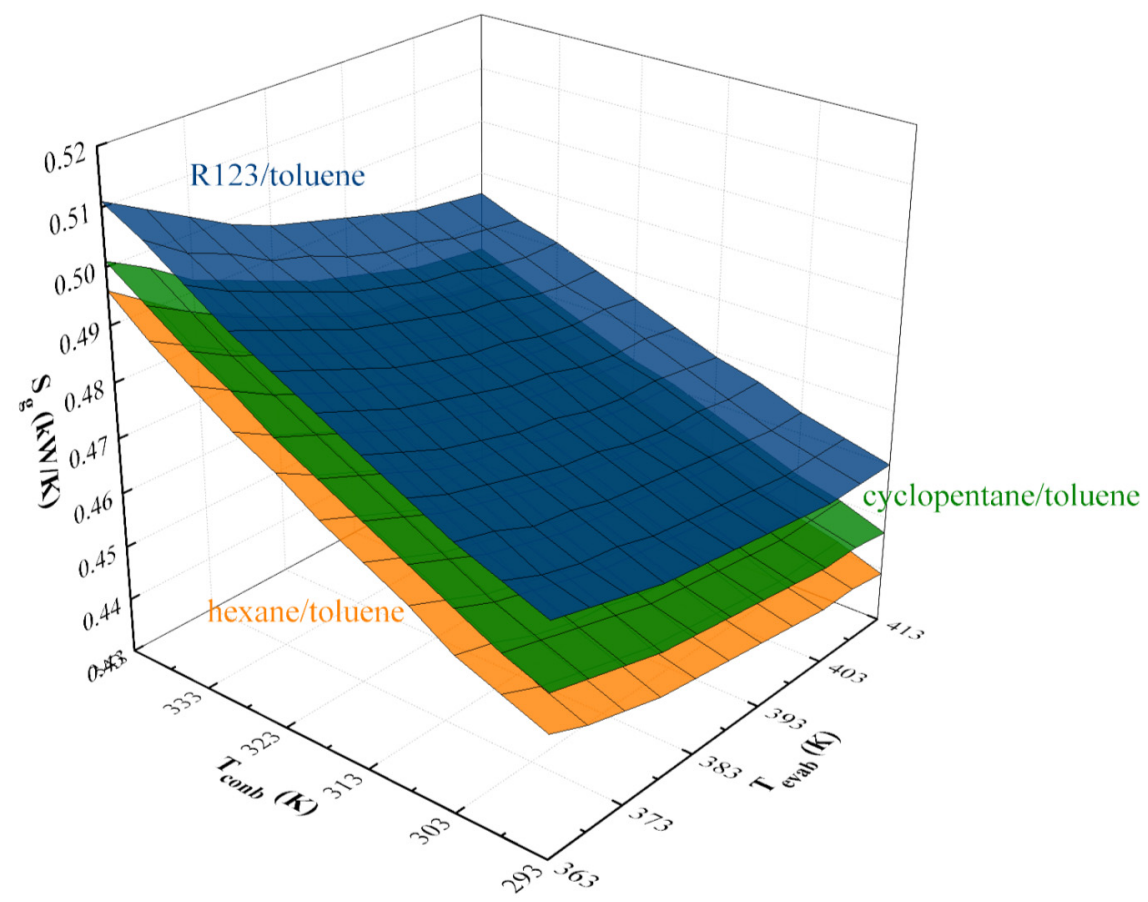

(b)

Figure 6. Cont. 


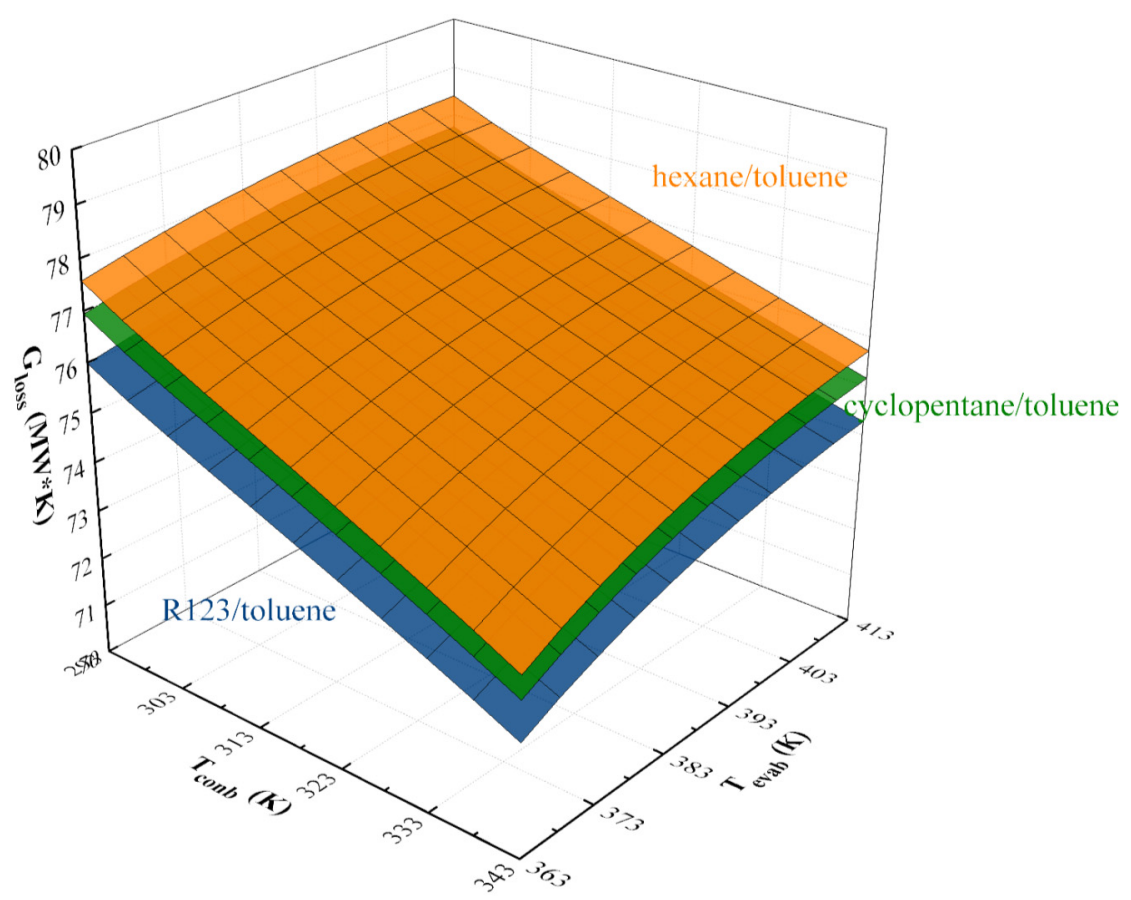

(c)

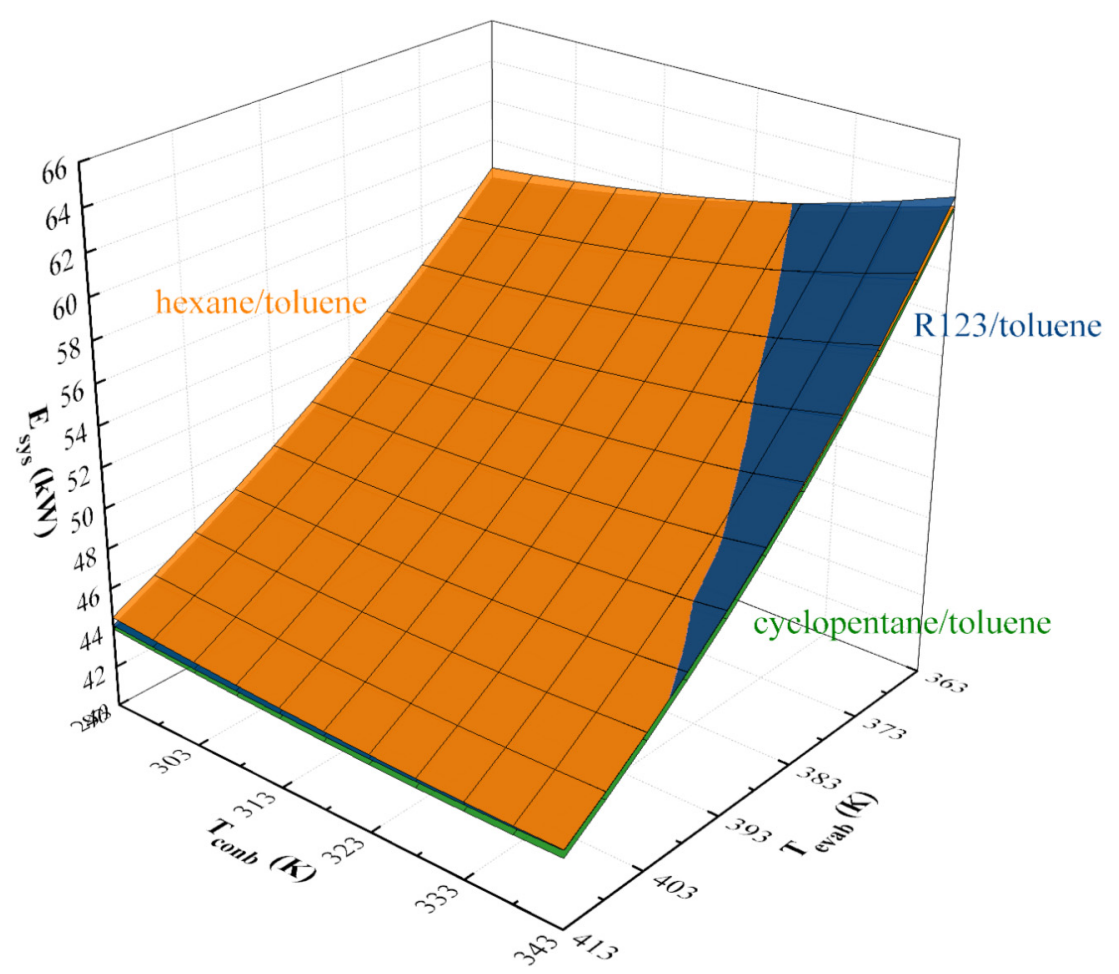

(d)

Figure 6. The effect of evaporation and condensation temperature of LT loop: (a) Power output; (b) entropy generation rate; (c) entransy loss rate; (d) exergy loss.

Figure 6 also presents the effects of LT loop condensation temperature on system performance. when the LT loop condensation temperature rises, the LT loop pump export enthalpy increases gradually, leading to the increase of LT loop fluid mass flow rate. The LT loop expander work decreases under the comprehensive effect of LT loop fluid mass flow rate and expander specific enthalpy difference. 
Therefore, the net output power decreases. In addition, the enthalpy difference of R245fa/pentane in LT loop condenser keeps dropping, and the enthalpy difference of cooling water changes in a reverse trend. Therefore the water mass flow rate presents a downward trend under the combined influence of LT loop fluid mass flow rate and condenser enthalpy change, leading to a decline of the entropy flow out of system. Meanwhile, the section $c_{\mathrm{c}} \dot{m}_{\mathrm{c}} \ln \left(T_{14} / T_{0}\right)$ decreases entropy flow into the system both decrease accordingly, which eventually leads to the increase of entropy generation rate. There is a reverse relationship between system irreversible loss and LT loop condensation temperature. In addition, the entransy flowing into the water decreases and its portion is greater than the decrement of the entransy loss released into the environment, so the entransy outflow of the system keeping rising, and the total entransy loss rate keeps dropping accordingly, as shown in Figure 6c.

As presented in Figure $6 b, c$, the net power output has a position correlation with entransy loss rate, and is correlated with entropy generation rate inversely. Figure $6 \mathrm{~d}$ indicates that the variation of exergy loss has an inflection point, and the various condensation temperatures corresponding to the lowest exergy loss are different. Therefore, the exergy analysis cannot be carried out for horizontal contrast under different environmental parameters.

\subsection{Effect of Superheating Degree and PPTD of HT Loop}

Figure $7 \mathrm{a}, \mathrm{b}$ show the variation of entropy generation rate and entransy loss rate with the superheating degree and PPTD using hexane/toluene, cyclopentane/toluene, and R123/toluene. The temperatures are set that: $T_{\text {eva }}=513 \mathrm{~K}, T_{\text {con }}=423 \mathrm{~K}, T_{\text {evab }}=413 \mathrm{~K}$, and $T_{\text {conb }}=303 \mathrm{~K}$. The PPTD varies from $20 \mathrm{~K}$ to $40 \mathrm{~K}$, and the superheating degree varies from $0 \mathrm{~K}$ to $20 \mathrm{~K}$.

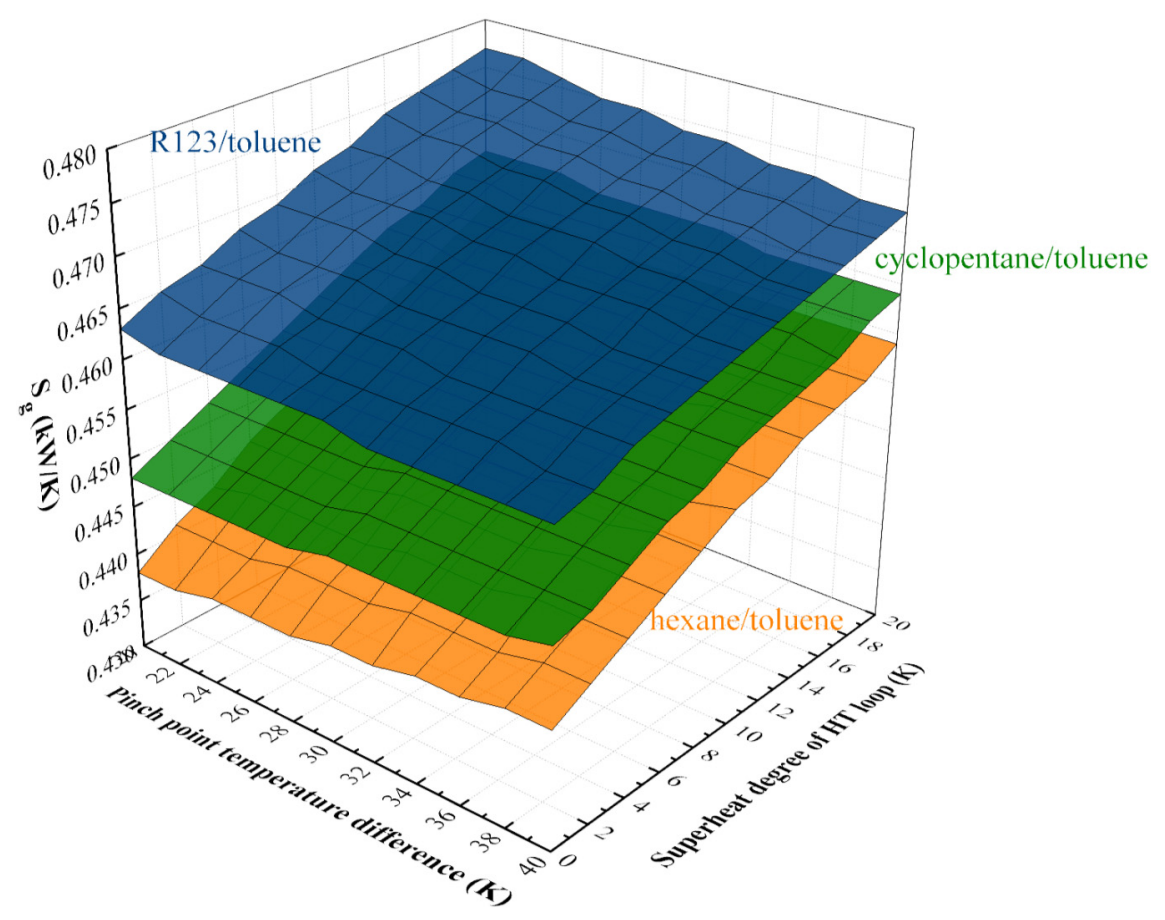

(a)

Figure 7. Cont. 


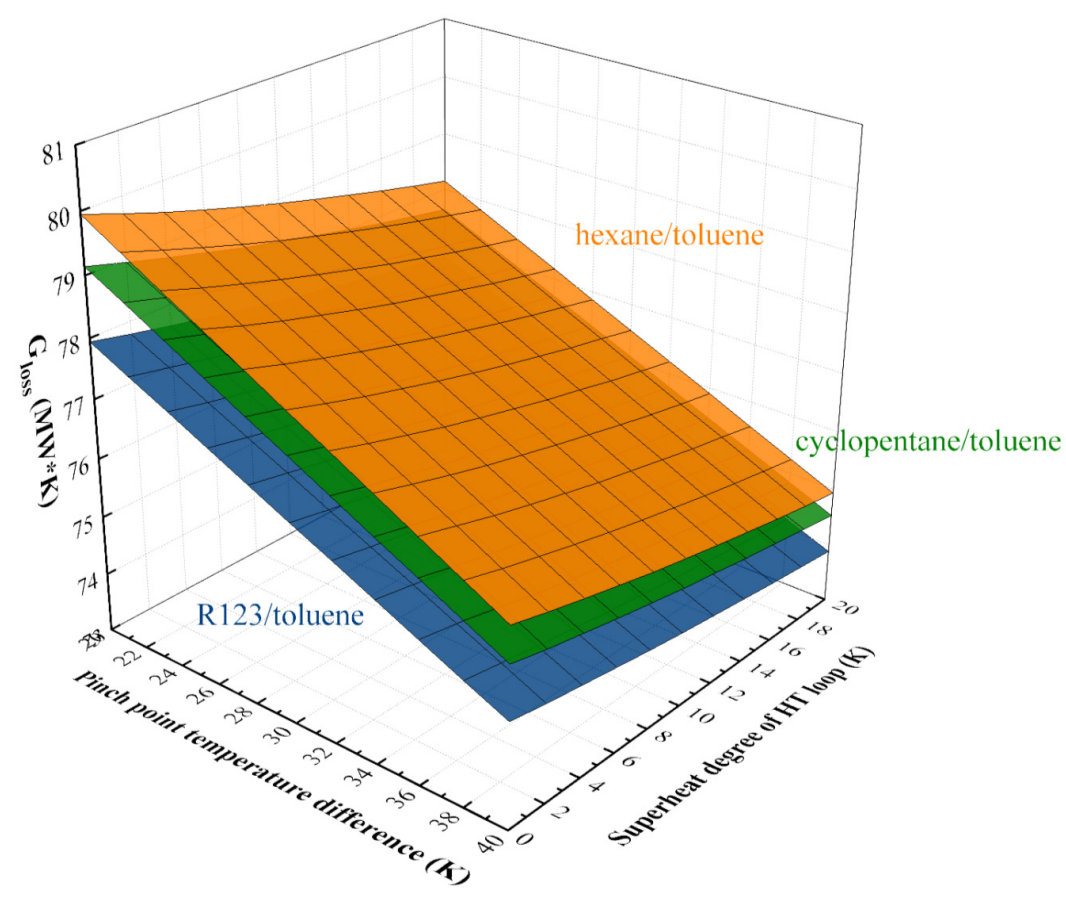

(b)

Figure 7. Effects of superheating degree and pinch point temperature difference of HT loop: (a) Entropy generation rate; $(\mathbf{b})$ entransy loss rate.

The entropy generation rate and entransy loss rate for the three mixtures have a similar behavior to superheating degree and PPTD as Figure 7a. When the superheating degree increases, the expander import temperature increases, and the specific enthalpy at HT loop expander import and export both increase. The HT loop mixture mass flow rate gradually decreases, resulting in the decrease of specific enthalpy difference in HT loop expander. Thus, the expander work keeps decreasing, which eventually causes the dropping of system net output power. Meanwhile, the required mass flow of LT loop mixture would be less because of the decrease of the enthalpy change in LT loop expander. The required water mass flow rate will reduce accordingly, thus the entropy generation rate increases with the increase of both entropy inflow and outflow. The system using R123/toluene has the highest entropy generation which varies from $0.463 \mathrm{~kW} / \mathrm{K}$ to $0.477 \mathrm{~kW} / \mathrm{K}$, while the lowest entropy generation is obtained by hexane/toluene in the range of $0.438-0.460 \mathrm{~kW} / \mathrm{K}$. In addition, when the PPTD increases, the entropy generation for hexane/toluene and cyclopentane/toluene increases and the one for R123/toluene yields a reverse trend. Despite that PPTD has an effect on the variation of exhaust gas heat in HT loop evaporator and then affects the subsequent parameters, the effect of PPTD on entropy generation rate could be negligible.

Figure $7 \mathrm{~b}$ presents that the entransy loss rate decreases with the increase of both superheating degree and PPTD, and the highest entransy loss is obtained by the system using hexane/toluene, followed by ones using cyclopentane/toluene and R123/toluene successively. For the system using hexane/toluene, when the superheating degree increases at a specified PPTD of $20 \mathrm{~K}$, the entransy loss rate decreases from $79.95 \mathrm{MW} \cdot \mathrm{K}$ to $78.15 \mathrm{MW} \cdot \mathrm{K}$. The entransy flowing into the system keeps unchanged when the superheating degree varies, while HT loop mixture mass flow rate and the system output power both decrease. The heat released to the environment increases because $c_{\mathcal{C}} \dot{m}_{\mathcal{C}}\left(T_{14}-T_{0}\right)$ and the system output power vary in different degrees as Equation (29), leading to the increase of entransy flowing out of the system. The entransy outflow increases because that the flow absorbed from cooling water is less than that released to the environment. Therefore, the entransy loss rate decreases with the increase of superheating degree. Besides, when the PPTD increases gradually, the temperature and specific enthalpy of exhaust gas in HT loop evaporator export both increase, while the required mass 
flow of HT loop working fluid decreases, leading to the decrease of mass flow rate of LT loop working fluid and cooling water successively. The specific enthalpies in all state points will not be affected, so the net power output decreases due to the reduction in expander work. The expander work decrement is greater than the heat capacity absorbed by cold water from the environment, resulting in the increase of system heat flow released to the environment and entransy outflow. Therefore, the system entransy loss rate decreases with the increase of PPTD.

\subsection{Effects of Working Fluid Mixture Component}

In this section, the influence of working fluid mixture component on entransy loss and entropy generation rate is shown in Figure 8a,b. The evaporation temperature and condensation temperature of HT loop are $503 \mathrm{~K}$ and $403 \mathrm{~K}$, respectively, and the evaporation temperature and condensation temperature of LT loop are $393 \mathrm{~K}$ and $303 \mathrm{~K}$, respectively.

Figure 8 a shows the variation of entransy loss rate with mass fraction of toluene. When the toluene mass fraction increases from 0 to 1 , the entransy loss rate for hexane/toluene decreases from 81.09 $\mathrm{MW} \cdot \mathrm{K}$ to $71.20 \mathrm{MW} \cdot \mathrm{K}$, while the ones for cyclopentane/toluene and R123/toluene both decrease first and then increase. The entransy loss rate for cyclopentane/toluene decreases from $71.20 \mathrm{MW} \cdot \mathrm{K}$ to 70.85 $\mathrm{MW} \cdot \mathrm{K}$ at the toluene mass fraction of 0.8 and then increases to $78.25 \mathrm{MW} \cdot \mathrm{K}$. Meanwhile, the toluene mass faction for the system using R123/toluene increases just from 0.4 to 1.0 restricted by the maximum evaporation temperature. The range of the entransy loss rate for R123/toluene is 70.46-71.76 MW.K and the minimum is $70.46 \mathrm{MW} \cdot \mathrm{K}$ at the mass fraction of 0.7 . The entransy loss rate for hexane/toluene is significantly higher than that for cyclopentane/toluene and R123/toluene because of the high specific enthalpy than other mixtures at the same evaporation temperature. Meanwhile, the system power output for hexane/toluene is greater than other mixtures. Therefore, the system using hexane/toluene has better heat transfer characteristic.

As observed in Figure 8b, the entropy generation rate yields a reverse trend to the entransy loss rate. The entropy generation rate for hexane/toluene increases gradually from $0.202 \mathrm{~kW} / \mathrm{K}$ to 0.321 $\mathrm{kW} / \mathrm{K}$, while the ones for cyclopentane/toluene and R123/toluene both increase first and then decrease again. The entropy generation rate for cyclopentane/toluene is in the range of $0.236-0.325 \mathrm{~kW} / \mathrm{K}$ with the maximum value of $0.325 \mathrm{~kW} / \mathrm{K}$ at the mass fraction of 0.8 . The entransy loss rate for R123/toluene increases from $0.315 \mathrm{~kW} / \mathrm{K}$ to $0.321 \mathrm{~kW} / \mathrm{K}$ with the maximum of $0.330 \mathrm{~kW} / \mathrm{K}$ at the mass fraction of 0.7 . The system using R123/toluene owns the highest entropy generation rate, while the lowest entropy generation rate is obtained by hexane/toluene.

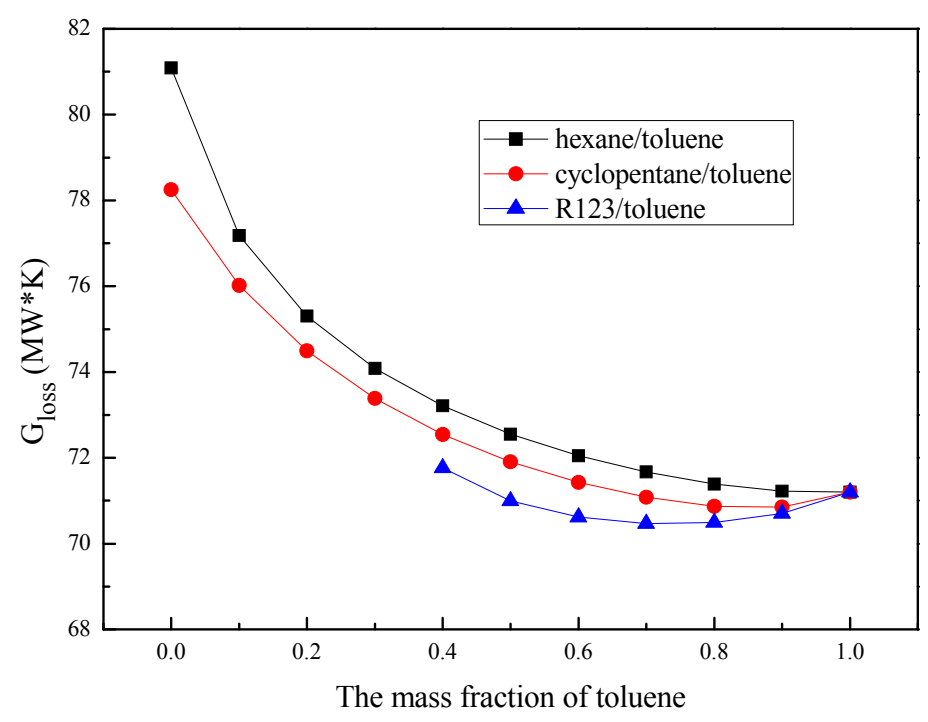

(a)

Figure 8. Cont. 


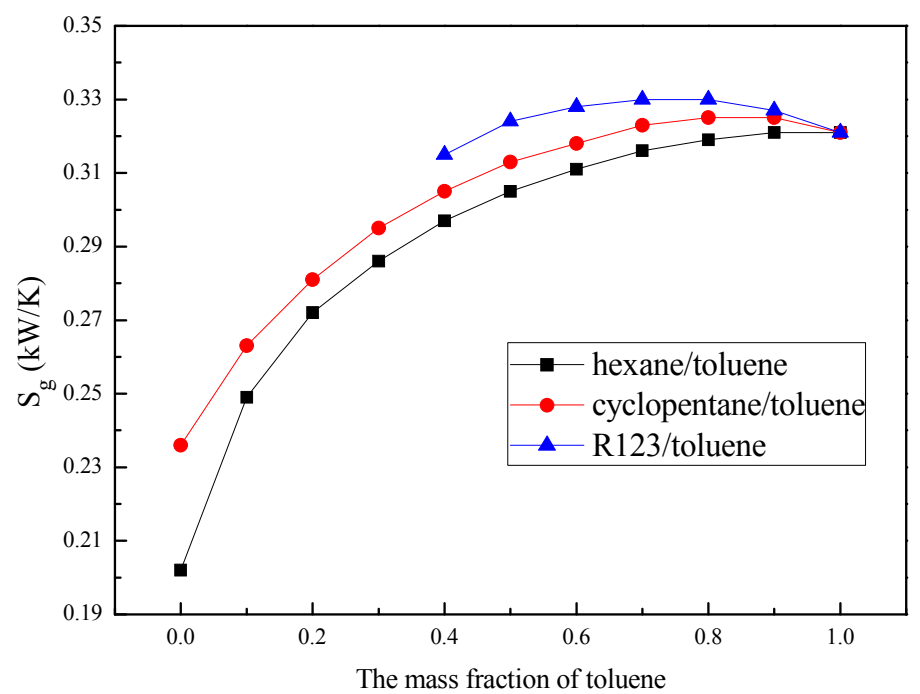

(b)

Figure 8. Effects of the working fluid mixture component: (a) Variation of the entransy loss rate; (b) variation of the entropy generation rate.

\section{Conclusions}

The exergy, entropy, and entransy analysis of DORC using mixture fluids (hexane/toluene, cyclopentane/toluene and R123/toluene) have been investigated. Effects of evaporation temperature and condensation temperature of HT loop, evaporation temperature and condensation temperature of LT loop, superheating degree, PPTD and working fluid mixture component on system exergy loss, entropy generation rate, entransy loss rate, and entransy efficiency are discussed. The analysis process is mainly through the combination of REFPROP and MATLAB. The major conclusions drawn from the simulation are:

- Hexane/toluene, cyclopentane/toluene, and R123/toluene are selected as high-temperature working fluids, and detailed analysis are proceeded under constant heat source condition. When the evaporator inlet temperature and condenser outlet temperature change, although the optimal evaporation temperature and maximum output power is different, the variation characteristics of entropy generation rate, entransy loss rate, entransy efficiency, and exergy loss are similar. Hence, the effects of operation temperature on these objects do not matter whatever the working fluid.

- The system net power output and entransy loss rate both increase first and then decrease as the HT evaporation temperature increases, while decrease as the HT or LT condensation temperature increases. The entropy generation rate and entransy efficiency show opposite variation.

- The curve characteristic of entransy loss rate is same as that of system power output, while the entropy generation rate yields a reverse trend to the entransy efficiency. The proposed method of the entropy and entransy analysis could be used for system optimization. Whereas the exergy analysis could be only utilized under fixed stream conditions.

- The entransy loss rate decreases with the increase of both superheating degree and PPTD. The entropy generation rate increases as superheating degree increases while PPTD has no effect on it. The entransy loss rate for hexane/toluene keeps dropping with the rising mass fraction of toluene, but that for cyclopentane/toluene and R123/toluene it decreases first and then increases. R123/toluene owns the lowest entransy loss rate and the highest entransy loss rate is obtained by hexane/toluene under same mass fraction. The entropy generation for three mixtures show a reverse trend with entransy loss rate. 
Author Contributions: Conceived the presented idea, S.W. and Y.-Q.F.; theory and computation, Q.W., W.Z. and X.W.; analytical method verifying. Y.-Z.L., Y.W. and L.Y. All authors have read and agreed to the published version of the manuscript.

Funding: This research work has been supported by the National Natural Science Foundation of China (51806081), the Key Research and Development Program of Jiangsu Province, China (BE2019009-4), the Natural Science Foundation of Jiangsu Province (BK20180882), the China Postdoctoral Science Foundation (2018M632241), the 2019 Scholarship of the Knowledge Center on Organic Rankne Cycle (KCORC, www.kcorc.org), the Key Research and Development Program of Zhenjiang City, China (SH2019008), and the Key Project of Taizhou New Energy Research Institute, Jiangsu University, China (2018-20).

Conflicts of Interest: The authors declare no conflict of interest.

\section{Nomenclature}

c specific heat capacity, $\mathrm{J} / \mathrm{kg} \cdot \mathrm{K}$

e specific exergy, $\mathrm{J} / \mathrm{kg}$

E exergy loss, W

$\mathrm{G}_{\text {loss }} \quad$ entransy loss rate, $\mathrm{W} \cdot \mathrm{K}$

$h \quad$ specific enthalpy, $\mathrm{J} / \mathrm{kg}$

$m \quad$ mass flow rate, $\mathrm{kg} / \mathrm{s}$

$Q \quad$ heat quantity, $\mathrm{J}$

$S_{\mathrm{g}} \quad$ entropy generation rate, $\mathrm{W} / \mathrm{K}$

$S_{\mathrm{f}} \quad$ entropy flow rate, $\mathrm{W} / \mathrm{K}$

$\Delta S \quad$ entropy change rate, $\mathrm{W} / \mathrm{K}$

$T$ temperature, $\mathrm{K}$

$W$ power, $\mathrm{W}$

$\eta \quad$ Efficiency

Hi heat exchanger with number $\mathrm{i}, \mathrm{i}=1,2,3,4$

HT high temperature

LT low temperature

Pi pump with number $i, i=1,2$

$\mathrm{Ti}$ expander with number $\mathrm{i}, \mathrm{i}=1,2$

subscripts

$b$ parameters in LT cycle

con condensation

dis dissipation

eva evaporation

glide temperature slip

$g, c \quad$ heat, cold source

op optimal

$p \quad$ pump

$r \quad$ working fluid

sub Supercooling

sup Superheating

sys System

$t \quad$ expander

1-17 state point of T-s graph

$2 s, 6 s \quad$ Corresponding isentropic point

\section{References}

1. Dai, Y.P.; Wang, J.F.; Gao, L. Parametric optimization and comparative study of organic Rankine cycle (ORC) for low grade waste heat recovery. Energy Convers. Manag. 2009, 50, 576-582. [CrossRef]

2. Bombarda, P.; Invernizzi, C.M.; Pietra, C. Heat recovery from Diesel engines: A thermodynamic comparison between Kalina and ORC cycles. Appl. Therm. Eng. 2010, 30, 212-219. [CrossRef] 
3. Feng, Y.Q.; Li, B.X.; Yang, J.F.; Shi, Y. Comparison between regenerative organic Rankine cycle (RORC) and basic organic Rankine cycle (BORC) based on thermoeconomic multi-objective optimization considering exergy efficiency and levelized energy cost (LEC). Energy Convers. Manag. 2015, 96, 58-71. [CrossRef]

4. Mago, P.J.; Chamra, L.M.; Srinivasan, K.; Somayaji, S. An examination of regenerative organic Rankine cycles using dry fluids. Appl. Therm. Eng. 2008, 28, 998-1007. [CrossRef]

5. Pei, G.; Li, J.; Ji, J. Analysis of low temperature solar thermal electric generation using regenerative Organic Rankine Cycle. Appl. Therm. Eng. 2010, 30, 998-1004. [CrossRef]

6. Roy, J.P.; Misra, A. Parametric optimization and performance analysis of a regenerative organic Rankine cycle using R-123 for waste heat recovery. Energy 2012, 39, 227-235. [CrossRef]

7. Franco, A. Power production from a moderate temperature geothermal resource with regenerative organic Rankine cycles. Energy Sustain. Dev. 2011, 15, 411-419. [CrossRef]

8. Li, M.Q.; Wang, J.F.; He, W.F.; Gao, L.; Wang, B.; Ma, S.L.; Dai, Y.P. Construction of preliminary test of a low-temperature regenerative organic Rankine cycle (ORC) using R123. Renew. Energy 2013, 57, $216-222$. [CrossRef]

9. Li, T.L.; Wang, Q.L.; Zhu, J.L.; Hu, K.; Fu, W.C. Thermodynamic optimization of organic Rankine cycle using two-stage evaporation. Renew. Energy 2015, 75, 654-664. [CrossRef]

10. Sun, Y.R.; Lu, J.; Wang, J.Q.; Li, T.L.; Li, Y.J.; Hou, Y.S.; Zhu, J.L. Performance improvement of two-stage serial organic Rankine cycle (TSORC) integrated with absorption refrigeration (AR) for geothermal power generation. Geothermics 2017, 69, 110-118. [CrossRef]

11. Yuan, Y.; Xu, G.; Quan, Y.; Wu, H.; Song, G.; Gong, W.; Luo, X. Performance analysis of a new deep super-cooling two-stage organic Rankine cycle. Energy Convers. Manag. 2017, 148, 305-316. [CrossRef]

12. Xi, H.; Li, M.J.; Xu, C.; He, Y.L. Parametric optimization of regenerative organic Rankine cycle (ORC) for low grade waste heat recovery using genetic algorithm. Energy 2013, 58, 473-482. [CrossRef]

13. Shu, G.Q.; Liu, L.N.; Tian, H.; Wei, H.Q.; Yu, G.P. Parametric and working fluid analysis of a dual-loop organic Rankine cycle (DORC) used in engine waste heat recovery. Appl. Energy 2014, 113, 1188-1198. [CrossRef]

14. Choi, B.C.; Kim, Y.M. Thermodynamic analysis of a dual loop heat recovery system with trilateral cycle applied to exhaust gases of internal combustion engine for propulsion of the 6800 TEU container ship. Energy 2013, 58, 404-416. [CrossRef]

15. Panesar, A.S.; Morgan, R.E.; Miché, N.D.; Heikal, M.R. A novel organic Rankine cycle system with improved thermal stability and low global warming fluids. Int. Conf. Prod. 2014, 13, 6002. [CrossRef]

16. Boyaghchi, F.A.; Sohbatloo, A. Assessment and optimization of a novel solar driven natural gas liquefaction based on cascade ORC intergrated with linear Fresnel collectors. Energy Convers. Manag. 2018, 162, 77-89. [CrossRef]

17. Sun, Q.X.; Wang, Y.D.; Cheng, Z.Y.; Wang, J.F.; Zhao, P.; Dai, Y.P. Thermodynamic and economic optimization of a dual-pressure organic Rankine cycle driven by low-temperature heat source. Renew. Energy 2020, 147, 2822-2832. [CrossRef]

18. Oyewunmi, O.A.; Markides, C.N. Thermo-Economic and Heat Transfer Optimization of Working-Fluid Mixtures in a Low-Temperature Organic Rankine Cycle System. Energies 2016, 9, 448. [CrossRef]

19. Wang, E.H.; Yu, Z.B.; Collings, P. Dynamic control strategy of a distillation system for a composition-adjustable organic Rankine cycle. Energy 2017, 141, 1038-1051. [CrossRef]

20. Collings, P.; Yu, Z.B.; Wang, E.H. A dynamic organic Rankine cycle using a zeotropic mixture as the working fluid with composition tuning to match changing ambient conditions. Appl. Energy 2016, 171, 581-591. [CrossRef]

21. Oyewunmi, O.A.; Kirmse, C.J.W.; Pantaleo, A.M.; Markides, C.N. Performance of working-fluid mixtures in ORC-CHP systems for different heat-demand segments and heat-recovery temperature levels. Energy Convers. Mang. 2017, 148, 1508-1524. [CrossRef]

22. Oyewunmi, O.A.; Taleb, A.I.; Haslam, A.J.; Markides, C.N. On the use of SAFT-VR Mie for assessing large-glide fluorocarbon working-fluid mixtures in organic Rankine cycles. Appl. Energy 2016, 163, 263-282. [CrossRef]

23. Lecompte, S.; Ameel, B.; Ziviani, D.; van den Broek, M.; De Paepe, M. Exergy analysis of zeotropic mixtures as working fluids in Organic Rankine Cycles. Energy Convers. Manag. 2015, 82, 664-677. [CrossRef] 
24. Feng, Y.Q.; Luo, Q.H.; Wang, Q.; Wang, S.; He, Z.X.; Zhang, W.; Wang, X.; An, Q.S. Entropy and Entransy Dissipation Analysis of a Basic Organic Rankine Cycles (ORCs) to Recover Low-Grade Waste Heat Using Mixture Working Fluids. Entropy 2018, 20, 818. [CrossRef]

25. Zhang, T.; Zhu, T.; An, W.; Song, X.; Liu, L.; Liu, H. Unsteady analysis of a bottoming Organic Rankine Cycle for exhaust heat recovery from an Internal Combustion Engine using Monte Carlo simulation. Energy Convers Manag. 2016, 165, 878-892. [CrossRef]

26. Baldi, F.; Larsen, U.; Garbrielii, C. Comparison of different procedures for the optimization of a combined Diesel engine and organic Rankine cycle system based on ship operational profile. Ocean Eng. 2015, 110, 85-93. [CrossRef]

27. Neto, R.D.O.; Sotomonte, C.A.R.; Coronado, C.J.R.; Nascimento, M.A.R. Technical and economic analyses of waste heat energy recovery from internal combustion engines by the Organic Rankine Cycle. Energy Convers. Manag. 2016, 129, 168-179. [CrossRef]

28. Song, J.; Gu, C.W. Parametric analysis of a dual loop Organic Rankine Cycle (ORC) system for engine waste heat recovery. Energy Convers. Manag. 2015, 105, 995-1005. [CrossRef]

29. Shu, G.Q.; Gao, Y.Y.; Tian, H.; Wei, Q.G.; Liang, X.Y. Study of mixtures based on hydrocarbons used in ORC (Organic Rankine Cycle) for engine waste heat recovery. Energy 2014, 74, 428-438. [CrossRef]

30. Lecompte, S.; Ameel, B.; Ziviani, D.; Broek, M.V.D.; Paepe, M.D. Exergy analysis of zeotropic mixtures as working fluids in Organic Rankine Cycles. Energy 2012, 44, 623-632. [CrossRef]

31. Feng, Y.Q.; Hung, T.C.; Zhang, Y.N.; Li, B.X.; Yang, J.F.; Shi, Y. Performance comparison of low-grade ORCs (organic Rankine cycles) using R245fa, pentane and their mixtures based on the thermoeconomic multi-objective optimization and decision makings. Energy 2015, 93, 2018-2029. [CrossRef]

32. Song, J.; Gu, C.W. Performance analysis of a dual-loop organic Rankine cycle (ORC) system with wet steam expansion for engine waste heat recovery. Appl. Energy 2015, 56, 280-289. [CrossRef]

33. Lemmon, E.W.; Huber, M.L.; Mclinden, M.O. NIST Standard Reference Database 23: Reference fluid thermodynamic and transport properties-REFPROP, version 9.1, Standard Reference Data Program, National Institute of Standards and Technology. NIST NSRDS 2010, 22, 1-49.

34. Zhao, K.H.; Luo, W.Y. Thermal; High Education Press: Beijing, China, 2002; pp. 1-222. (In Chinese)

35. Guo, Z.Y.; Zhu, H.Y.; Liang, X.G. Entransy-A physical quantity describing heat transfer ability. Int. J. Heat Mass Transfer. 2007, 50, 2545-2556. [CrossRef]

36. Cheng, X.T.; Liang, X.G. Entransy loss in thermodynamic processes and its application. Energy 2012, 41, 964-972. [CrossRef]

37. Li, T.L.; Yuan, Z.H.; Zhu, J.L. Entransy dissipation/loss-based optimization of two-stage organic Rankine cycle (TSORC) with R245fa for geothermal power generation. Sci. China Technol. Sci. 2016, 59, 1524-1536. [CrossRef]

38. Zhu, Y.D.; Hu, Z.; Zhou, Y.D.; Jiang, L.; Yu, L.J. Applicability of entropy, entransy and exergy analyses to the optimization of the Organic Rankine Cycle. Energy Convers. Manag. 2014, 88, 267-276. [CrossRef] 